\title{
In Good Times and in Bad:
}

\section{A Longitudinal Analysis of the Impact of Bereavement on Self-Esteem and Life Satisfaction in Couples}

Anne K. Reitz ${ }^{1}$, Rebekka Weidmann²,3, Jenna Wünsche ${ }^{3}$, Janina L. Bühler ${ }^{3,4}$, Robert P. Burriss $^{3}, \&$ Alexander Grob ${ }^{3}$

${ }^{1}$ Tilburg University, ${ }^{2}$ Michigan State University, ${ }^{3}$ University of Basel, ${ }^{4}$ Heidelberg University

This manuscript has been peer reviewed and accepted for publication in European Journal of Personality.

\section{Author Note}

Correspondence concerning this article should be addressed to Anne K. Reitz, Tilburg University, Department of Developmental Psychology, Simon building S315, PO Box 90153, 5000 LE TILBURG, The Netherlands, +31 1346648 26, a.k.reitz@tilburguniversity.edu.

This project has received funding from the European Union's Horizon 2020 research and innovation programme under the Marie Skłodowska-Curie grant agreement No 846839, awarded to Dr. Anne Reitz. This study (the data collection for the CouPers project) was funded by the Swiss National Science Foundation (SNSF 100019_162697).

Author Contributions (following the CRediT taxonomy): Anne K. Reitz: Conceptualization, Data curation, Methodology, Project administration, Formal analysis, Writing - original draft; Rebekka Weidmann: Formal analysis, Methodology, Visualization, Investigation; Jenna Wünsche, Janina L. Bühler, Robert P. Burriss: Investigation; Alexander Grob: Funding acquisition. All authors contributed to Writing - review and editing.

The authors are grateful for the research assistance of Sabrina Brunner, Fabienne Fend, and Rahel Hütten. The authors also thank Prof. Dr. Niall Bolger for helpful feedback on the preregistration. 


\begin{abstract}
This study examines the impact of bereavement on self-esteem and life satisfaction in both partners of a romantic couple. We investigate the moderating effects of the type of the lost relationship (close family, close friends/others) and romantic relationship characteristics (daily social support, responsiveness-closeness, self-disclosure). We examined 1,238 individuals in 619 male-female couples from the ages 18 to $81(M[S D]=31.97$ years [13.26]). Both partners completed questionnaires at two assessments that were 20 months $(S D=2.02$ months) apart, in between which $n=216$ individuals were bereaved. Actor-partner interdependence models showed that bereavement did not predict later self-esteem or life satisfaction in either of the partners. The relationship characteristics and the type of lost relationship did not moderate the effects. The subjective meaning and distress of the loss predicted later self-esteem and life satisfaction. The self-esteem increase was larger for bereaved with a positive/neutral than for bereaved with a negative meaning. We found a partner effect on self-esteem for the group of bereaved who reported a negative meaning. The findings demonstrate that bereavement can impact romantic partners' self-esteem and that the subjective experience of bereavement helps understand individual differences in the effect of bereavement on self-esteem and life satisfaction.
\end{abstract}

Keywords: bereavement, self-esteem, life satisfaction, close relationships, longitudinal dyadic data analysis 


\section{In Good Times and in Bad: A Longitudinal Analysis of the Impact of Bereavement on Self-Esteem and Life Satisfaction in Couples}

Most people report the death of a loved one as their worst life event (Breslau et al., 1998). Compared to other negative life events, such as serious illness, violent crime, or war, nearly everyone experiences the loss of a loved one (i.e., bereavement), at some point in their life (Keyes et al., 2014). Regardless of the high prevalence, most individuals experience bereavement as a painful and devastating event that disrupts everyday life and can shape developmental trajectories (Diener, Lucas, \& Scollon, 2006; Luhmann, Hofmann, Eid, \& Lucas, 2012). A wide range of negative consequences of bereavement have been reported, not only health problems, but also psychopathological outcomes, including depression, anxiety, and PTSD (e.g., Keyes et al., 2014; for a review, see Stroebe, Schut, \& Stroebe, 2007).

Much less is known about the consequences of bereavement for positive outcomes, which might be due to the artificial separation of traditional clinical psychology and positive and personality psychology (Johnson \& Wood, 2017). However, there is a need to extend the range of possible consequences of stressful life events beyond psychopathology to understand the whole psychological experience. Knowledge of positive outcomes is also needed to improve prevention and intervention programs aimed not only at reducing stress, but also at improving well-being, resilience, and personal and posttraumatic growth (Duckworth, Steen, \& Seligman, 2005; Jayawickreme \& Blackie, 2014; Noftle, Schnitker, \& Robins, 2011).

The present study examines the effect of bereavement on two major psychological adjustment outcomes: self-esteem (a person's evaluation of their personal value) and life satisfaction (a person's overall evaluation of their life). Both factors are key individual resources for physical and mental health (Diener \& Chan, 2011; Orth \& Robins, 2014), which is another reason why we need to extend our knowledge about their antecedents. Lifespan theory has posited that environmental changes, such as major life events, can trigger change 
in broad traits (Baltes, 1987; Sameroff, 2010). Especially bereavement might affect selfesteem and life satisfaction due to the importance of social relationships for these outcomes (Leary \& Baumeister, 2000; Magnusson, 1990). Yet, empirical evidence is inconclusive, and many major questions remain unanswered. We aim to address several of these questions and to overcome several methodological constraints of previous research.

First, we use a quasi-experimental longitudinal design to examine the effects of bereavement on change in self-esteem and life satisfaction in romantic couples. We compare mean-level changes of those who did and those who did not experience a bereavement in between two assessments. Using a control group allows us to disentangle age-related change from event-induced change.

Second, whereas the impact of spousal and child loss is relatively well understood (for reviews, see Kristiansen et al., 2019; Naef, Ward, Mahrer-Imhof, \& Grande, 2013), less is known about the effects of losing less close but still important types of relationships including other family members and friends, which is the focus of the present study.

Third, research on the impact of bereavement has traditionally focused on individuals and has neglected that it is not experienced in isolation. However, bereavement might affect romantic partners, too, which can be derived from theoretical models. Dynamic interactionism theory posits that personality and (romantic) relationships are dynamically intertwined (Neyer, Mund, \& Zimmermann, 2014). Interdependence theory states that changes in one member of the dyad influence changes in the other (Van Lange \& Balliet, 2015). We therefore use dyadic couple data to study the interdependent development of both couple members' self-esteem and life satisfaction after bereavement. This evidence will inform theory and practice as it would call for a broader, more contextualized perspective that includes the close social environment to understand changes following bereavement. 
Fourth, individuals differ considerably in their reaction to bereavement, but little is known about the contributing factors to this variability (Burke, Shrout, \& Bolger, 2007; Galatzer-Levy \& Bonanno, 2012). This variability may be better understood by considering the contextualized nature of human development (Baltes et al., 2006; Sameroff, 2010). We therefore study couple-level moderators: type of lost relationship (close family versus close friends and others) and romantic relationship characteristics (social support, responsiveness, closeness, self-disclosure). We assess the relationship characteristics with daily couple interactions using self- and partner-reports in daily diaries across 14 days.

\section{Stability and Change in Self-Esteem and Life Satisfaction}

Self-esteem and life satisfaction show a moderate degree of stability over time that is comparable to personality traits (e.g., Donnellan, Kenny, Trzesniewski, Lucas, \& Conger, 2012; Kuster \& Orth, 2013; Lucas \& Donnellan, 2007). Yet, research has also indicated that self-esteem and life satisfaction can change: Not only do they show characteristic mean-level changes across the lifespan (see Baird, Lucas, \& Donnellan, 2010; Orth, Erol, \& Luciano, 2018) but they also show substantial individual variability in these change trajectories (Lucas \& Donnellan, 2007; Ehrhardt \& Saris, 2000). The finding that self-esteem and life satisfaction are changeable leads to the question as to what factors drive this change.

Lifespan theory (Baltes, Lindenberger, \& Staudinger, 2006) and the related transactional perspectives (Sameroff, 2010) have postulated that environmental changes such as life events can shape the course of individual development. Lifespan theory (Baltes, 1987) distinguishes different categories of influences on development of which two play a major role in self-esteem and life-satisfaction development. Age-graded influences (i.e., events highly correlated with chronological age) are predictable in their onset and similar in their direction among people in a certain age group, which is why they are considered a major driver of normative mean-level lifespan changes (Robins \& Trzesniewski, 2005). Non- 
normative life events are not clearly tied to a certain developmental phase; their occurrence and patterning is not applicable to most people of a certain age, but they are rather unpredictable, which is why they are considered a driver of individual variability in development. Bereavement is one such non-normative life event, especially if studied as the response to a wide range of losses, which can happen across the entire lifespan (unlike specific losses such as widowhood, which is more frequent in old than in young age).

The theory has been supported by various studies showing that life events can shape the development of personality, life satisfaction, and self-esteem (e.g., Denissen, Luhmann, Chung, \& Bleidorn, 2019; Lucas, 2007; Orth \& Luciano, 2015). Most research has focused on age-graded life events (e.g., education-to-work transition; Reitz, Shrout, Denissen, Dufner, \& Bolger, 2020; parenthood; Bleidorn et al., 2016). Non-normative life events such as bereavement have received less attention in this literature, with some exceptions (e.g., Chopik, 2018; for a literature review of the study variables, see below). Yet, more knowledge on the impact of non-normative events on these characteristics is needed to better understand why not everybody follows the general, predictable lifespan course. This research can inform theories and programs to prevent and treat negative trajectories and promote positive ones.

\section{The Impact of Bereavement on Self-Esteem and Life Satisfaction}

Self-esteem theories focus mostly on the influence of success and failure (James, 1890), such as social inclusion (sociometer theory; Leary \& Baumeister, 2000) or social status (hierometer theory; Mahadevan, Gregg, \& Sedikides, 2019). These social experiences carry information about an individual's qualities (e.g., gauging their relational value; Leary \& Baumeister, 2000). An interesting and yet unanswered question is whether social events such as bereavement, which is fully outside the control of the individual and hence does not carry such information, also affect self-esteem. Contemporary theories that emphasize the role of the social environment for self-evaluations suggest that the loss of an important relationship 
diminishes the social network and social resources, which might lead to a decline in selfesteem (Leary \& Baumeister, 2000; Sameroff, 2010). Another argument in support of bereavement-related declines in self-esteem originates from Lerner's (1980) Just World Theory, which states that people assume that the world is not a random but an orderly place where people get what they deserve. As a result, people might tend to adopt self-defeating beliefs of blame and self-devaluation following negative, uncontrollable events, which could lead to a decrease in their self-esteem (Callan, Kay, \& Dawtry, 2014).

Existing research is inconclusive regarding whether and how bereavement affects selfesteem but generally points to negative effects. Most research examined bereavement only as part of an aggregated negative life-event measure, which does not permit drawing specific conclusions for bereavement. These studies mostly reported negative effects on self-esteem (Galambos, Barker, \& Krahn, 2006; Joiner, Katz, \& Angela, 1999; Orth \& Luciano, 2015). One study identified a significant negative effect only in one of three samples (Orth, Robins, \& Meier, 2009). A meta-analysis found increases in self-esteem after negative events (mostly illness) in prospective studies but decreases in self-esteem in studies with control groups (Mangelsdorf, Eid, \& Luhmann, 2019). This research highlights the importance of control groups; without them, changes cannot be clearly attributed to the event.

Studies that examined the sole impact of bereavement on self-esteem are scarce, especially on losses other than the partner, for which we only found two studies. Murrell, Meeks, and Walker (1991) found that bereavement (mostly friends but also family members) did not predict change in older adults' self-esteem. Similarly, Tetzner, Becker, and Baumert (2016) found no effects of the death of a parent in adolescents and young adults on changes in self-esteem. Concerning the loss of close family members (children, spouses), findings from cross-sectional (Mancini, Prati, \& Black, 2011; Wonch Hill, Cacciatore, Shreffler, \& Pritchard, 2017) and longitudinal studies (Montpetit, Bergeman, \& Bisconti, 2010; Van 
Baarsen, 2002) typically show a negative link between bereavement and self-esteem, although Carr (2004) found an increase in self-esteem among women after widowhood.

In the life satisfaction literature, there has been a long-standing debate about whether life events have a significant impact. Proponents of the set-point theory argue that subjective well-being changes, if at all, only briefly after major life events, but will inevitably return to the genetically determined set-point; recent evidence has, however, challenged this assumption and posits that lasting change is possible after life events (see Diener et al., 2006). Research mostly reported negative effects of bereavement, but it is often restricted to widowhood. Cross-sectional studies have shown a negative link between bereavement and life satisfaction after the loss of a spouse or child, particularly in men (Bratt, Stenström, \& Rennemark, 2017; Spahni, Bennett, \& Perrig-Chiello, 2016). Longitudinal panel studies have repeatedly shown that widowhood is related to considerable declines in life satisfaction that only returned closer to the baseline after 4-7 years (e.g., Infurna et al., 2017; Lucas, Clark, Georgellis, \& Diener, 2003; Lucas, 2007; Luhmann et al., 2012). However, there are also contrary findings, including that caregivers' life satisfaction increases more after the death than after the recovery of an ill spouse (Langner \& Furstenberg, 2019). Less is known about bereavement of other relationships than the partner, but Lundberg et al. (2018) found poorer well-being in a study on young adults who lost their parents.

In sum, theory and empirical evidence suggest a general negative effect of bereavement on self-esteem and life satisfaction. Evidence is, however, inconclusive, especially for losses other than widowhood, which might be partly due to differences in the type of the lost relationship and individual variability (both of which we discuss below) and in research designs (cross-sectional versus longitudinal data; availability of control groups). Research is also somewhat limited to specific age ranges (e.g., focus on older adults). This study uses a longitudinal control group design and a diverse sample in terms of type of losses 
that covers the adult lifespan and includes many younger adults to contribute novel evidence for whether bereavement impacts self-esteem and life satisfaction, as assumed by theory.

\section{Dyadic Bereavement Effects in Romantic Relationships}

When one partner experiences a negative life event, their romantic partner, commonly thought of as the closest and most important social relationship in adulthood (Kahn \& Antonucci, 1980), experiences it alongside them. Many theorists agree that adjustment to a stressful life event in general and grief especially is a dyadic phenomenon that affects both partners (e.g., Randall \& Bodenmann, 2009; Samios \& Baran, 2018; Shapiro, 2008).

Bereavement may impact changes in both partners' self-esteem and life satisfaction directly and indirectly: First, dyadic changes may occur because both partners had a bond with the deceased person. In this case, the loss would independently and directly affect both partners' self-esteem and life satisfaction via the intrapersonal processes described earlier.

Second, bereavement may affect both partners' self-esteem and life satisfaction indirectly via interpersonal processes. Distress may trigger negative relationship processes such as maladaptive communication styles, and the deteriorated relationship climate might be perceived as a sign of reduced own relational value (Leary \& Baumeister, 2000). Moreover, bereavement-related distress can be transmitted from one partner to the other via emotional contagion (Hatfield, Bensman, Thornton, \& Rapson, 2014). Hence, bereavement might affect both partners even if only one partner had a close bond with the deceased person. Both pathways are not mutually exclusive but may work together to shape the interdependent development of both couple members' self-esteem and life satisfaction after bereavement.

Several recent studies have reported that the impact of exposure to stress of one of the two partners extends beyond the individual to the romantic partner. For example, research on couples in which one partner has cancer or a chronic illness showed that the distress levels of both partners were related (for a meta-analysis, see Hagedoorn, Sanderman, Bolks, Tuinstra, 
\& Coyne, 2008). Research on terror attacks and combat experience also reported that survivors' and spouses' general psychological distress and PTSD symptoms were related (i.e., secondary traumatization; e.g., Dirkzwager, Bramsen, Ader, \& Van Der Ploeg, 2005; Renshaw et al., 2012). Such spill-over effects seem not only limited to life-threatening experiences, but also apply to other stressful events such as discrimination. A recent study found, for example, actor and partner effects of discriminatory experiences on health, depression, and relationship strain (Wofford, Defever, \& Chopik, 2019).

Given that romantic partners have similar levels of self-esteem and life satisfaction and that shared environments seem to contribute to their co-development (for a meta-analysis, see Orth et al., 2018), it is likely that life events such as bereavement impact both partners' self-esteem and life satisfaction. Yet, empirical evidence is scarce. The few studies that studied couples have mostly examined an event that affected both partners to a similar extent, such as parenthood (Dyrdal \& Lucas, 2013). Less is known about whether events in the life of one partner also affects the self-esteem and life satisfaction of the other partner, with few exceptions. A longitudinal study found that unemployment was linked to decreases in life satisfaction in both partners (Luhmann, Weiss, Hosoya, \& Eid, 2014). The current study expands the life event literature by examining, for the first time, whether bereavement, even if experienced by one partner, affects the other's self-esteem and life satisfaction.

\section{Individual Differences in the Effect of Bereavement on Self-Esteem and Life Satisfaction}

Individuals differ substantially in their psychological reactions to bereavement (e.g., Bonanno et al., 2002; Burke, Shrout, \& Bolger, 2007; for a review, see Stroebe et al., 2007). For most people, it is a difficult experience with negative but temporary effects on well-being and health. For some, the suffering is extreme and enduring and can lead to mental disorders. And yet others are not impacted at all, or even experience relief. More recently, the focus has shifted to growth as another possible response, which originates from the posttraumatic 
growth literature (Tedeschi \& Calhoun, 2004). Growth encompasses increases in psychological well-being and positive personality change in the aftermath of a stressful life event such as partner or child loss (for reviews, see Michael \& Cooper, 2013; Waugh, Kiemle, \& Slade, 2018). Research has also pointed to considerable individual differences in the degree to which life satisfaction changes in relation to spousal loss (although stable profiles were also found), but most studies are cross-sectional, with some exceptions (Bennett, Morselli, Spahni, \& Perrig-Chiello, 2019; Infurna et al., 2017). Research on selfesteem change after bereavement is lacking, but studies have reported substantial individual variability in self-esteem changes after negative life events (Tetzner et al., 2016), including growth trajectories (for a review, see Mangelsdorf et al., 2019).

The reasons for the individual variability in change in self-esteem and life satisfaction in the aftermath of bereavement are not well understood. The list of possible moderators includes situational, intrapersonal, and interpersonal factors (for a review, see Stroebe et al., 2007). Their review identified several gaps in the literature, of which we address both the role of the type of the lost relationship and the interpersonal factor of relationship characteristics.

\section{Type of the Lost Relationship}

Most longitudinal studies on bereavement effects on well-being and personality have examined partner loss (Asselmann \& Specht, 2020; Van Baarsen, 2002) and child loss (Infurna \& Lothar, 2017; Kim \& Hicks, 2015). Research on the consequences of the loss of other types of relationships remains limited, especially for self-esteem. Existing studies on life satisfaction suggest negative consequences of losing parents and friends, but many studies are cross-sectional (Lundberg et al., 2018; Moor \& de Graaf, 2016). Two longitudinal studies have, however, found negative effects of parental loss (Leopold \& Lechner, 2015) and death of a close friend on life satisfaction (Liu, Forbat, \& Anderson, 2019). We therefore anticipate a decline in life satisfaction and self-esteem when losing family members or friends, which 
might, however, be smaller than for spousal and child loss. A longitudinal study reported effects on life satisfaction after losses in people's social network, which were smaller than those observed for spousal and child loss (Infurna \& Mayer, 2019). The authors speculate that losing a close friend or family member might be less disruptive than losing a spouse or child.

Stroebe and colleagues (2007) concluded from their review that kinship relationship moderates the effects on health and that (adult) child loss is more disruptive than spousal loss (see also Moor \& de Graaf, 2016). It remains an open question whether the general pattern in line with the proverb "blood is thicker than water" applies to other types of relationships as well. A study based on the British Household Panel provided first evidence that this might be the case (Ballas \& Dorling, 2007). The researchers found happiness to have more negative associations with the death of a parent than with the death of non-family members. The reason for the more disruptive effects of losing kinship relationships might be that they are typically more interdependent, a key element of close relationships (Clark \& Lemay, 2010). In line with this notion, genetic relatedness was found to predict subjective closeness (Neyer \& Lang, 2003). From this research we anticipate stronger effects for losing close family members than for losing close friends and others.

\section{Romantic Relationship Characteristics}

Interpersonal factors play a crucial role in moderating psychological adjustment to bereavement (Bonanno et al., 2002; Infurna et al., 2017). Especially close (romantic) relationships can be a major source of support that can alleviate stress (Holt-Lunstad, 2018). Close relationships serve the function of providing a sense of security that both partners' wellbeing is protected and that they are responsive to one another (Clark \& Lemay, 2010). However, relationship qualities differ and accounting for such couple-level factors helps understand individual differences in self-esteem and life satisfaction development (Luhmann et al., 2014). We focus on four relationship characteristics. 
Social support has long been considered a powerful interpersonal protective factor in adjustment to stressors and trauma that may have direct and buffering effects on well-being (Cohen \& Wills, 1985; for meta-analyses on posttraumatic stress and growth, see Ozer, Best, Lipsey, \& Weiss, 2008; Prati \& Pietrantoni, 2009), but empirical evidence for bereavement is inconclusive. Some longitudinal studies suggest that social support from family and friends aids coping with the loss of and (unborn) children (Tseng, Cheng, Chen, Yang, \& Cheng, 2017) and is linked to lower loneliness (Utz, Swensson, Caserta, Lund, \& DeVries, 2014) and higher well-being (Stroebe, Zech, Stroebe, \& Abakoumkin, 2005). Most studies indicating a positive effect of support on adjusting to losses of other relationship types such as parents and siblings were cross-sectional (e.g., Lundberg et al., 2018). However, several other studies have reported no evidence supporting either a direct (for a review, see Miller, Smerglia, \& Bouchet, 2004) or buffering effect of social support on psychological adjustment to widowhood (Anusic \& Lucas, 2013; Utz et al., 2014; for a review, see Stroebe et al., 2005). There is a lack of research on the effects of support from the romantic partner on adjustment to bereavement. Studies on dyadic coping however point to the important role of the romantic partner in coping with grief (Bergstraesser, Inglin, Hornung, \& Landolt, 2015; Bodenmann, 2005). Other aspects of relationship quality than social support may protect from the negative effects of traumatic experiences (Neff \& Karney, 2007; for evidence, see Brosseau, McDonald, \& Stephen, 2011; Røsand, Slinning, Eberhard-Gran, Røysamb, \& Tambs, 2012). The interpersonal process model of intimacy describes several key aspects of adaptive romantic relationships characterized by closeness (Reis \& Shaver, 1988): It delineates that couples derive a sense of connectedness in their daily lives through a transactional intimacy process based on self-disclosure (communicating personally relevant information) and partner responsiveness (understanding, validating, caring). Research has provided evidence for the role of self- and partner-disclosure and responsiveness in daily life for intimacy, which was 
negatively related to the maladaptive demand-withdraw communication pattern (Laurenceau et al., 2005). The partners' pulling away from uncomfortable discussions might be harmful for coping with bereavement. A well-cultivated communication style and responsiveness were found to be crucial for successful coping (Randall \& Bodenmann, 2009; Reis \& Gable, 2015). Furthermore, higher levels of stress communication by the partner were linked with higher levels of post-traumatic growth in bereaved parents (Albuquerque, Narciso, \& Pereira, 2018). A review found yet no evidence that emotional disclosure facilitated adjustment to bereavement (Stroebe et al., 2005). Following the evidenced benefits of the described relationship characteristics, we anticipate weaker effects of bereavement among individuals and their partners if they show higher levels of social support, responsiveness, closeness, and self-disclosure in their every-day life as a couple.

In sum, many knowledge gaps persist with respect to the role of relationship characteristics in psychological adjustment to bereavement. Methodological and statistical challenges, which we aim to address in the present study, need to be overcome: Interpersonal moderators have often been assessed only after the bereavement, most evidence is crosssectional, support from the partners was not assessed, and relationship functioning was mostly assessed with questionnaires instead of daily reports of interactions that have higher ecological validity (Laurenceau, Feldman Barret, \& Rovine, 2005; Stroebe et al., 2007).

\section{The Present Study}

The goal of the present study was to examine whether bereavement due to the death of a close person predicts changes in self-esteem and life satisfaction of romantic partners. To the best of our knowledge, the experience of bereavement has only been investigated from the perspective of one person (the person who loses someone), whereas the perspective of that person's partner has not yet been considered. We therefore do not know whether one partner's bereavement predicts self-esteem and life satisfaction of the other partner. We used a dyadic 
approach to investigate change in self-esteem and life satisfaction in romantic couples. In these couples either none, one, or both partners reported the death of a close other (selfreported close family members versus close friends and others) in between two assessments. We examined whether bereavement predicts changes in both partners' self-esteem and life satisfaction using actor-partner interdependence models (APIMs).

We tested the following four preregistered hypotheses: Hypothesis 1: Bereavement has negative prospective effects on self-esteem and life satisfaction of the actor (the person reporting the bereavement). Hypothesis 2: Bereavement has negative prospective effects on self-esteem and life satisfaction of the partner (the partner of the person reporting the bereavement). We anticipated considerable individual variability in the prospective effects of bereavement on self-esteem and life satisfaction. We therefore examined whether changes were moderated by two sets of variables by testing the following two hypotheses: Hypothesis 3: The negative effect of bereavement on self-esteem and life satisfaction is stronger when the deceased individual was a close family member versus a non-close family member. Hypothesis 4: Relationship characteristics (i.e., daily interactions) moderate the effects of bereavement for both actor and partner (Hypotheses 1 and 2): The negative effect of bereavement on self-esteem and life satisfaction in both partners will be weaker when couples score higher in social support, responsiveness, closeness, and self-disclosure.

We tested the hypotheses with a sample from a large, longitudinal couple study. Longitudinal studies overcome the limitations of cross-sectional studies in which change might be due to post-hoc reconstructions rather than actual change (Jayawickreme et al., 2020; Luhmann et al., 2012). We also followed these authors' call for including a control group. We included both bereaved and non-bereaved couples in our test of Hypotheses 1 and 2 to increase confidence that changes are in fact due to the bereavement experience instead of age-related changes. The moderator effects (Hypotheses 3 and 4) could only be tested in the 
subsample of bereaved couples. To capture potentially protective relationship characteristics of these couples in real-life, we used 14-day diary reports at baseline. Such reports capture the dynamic nature of daily interactions more accurately than the more conventionally used retrospective, static assessments (Bolger, Davis, \& Rafaeli, 2003). We used both self- and partner-reports of daily interactions to obtain more accurate measures of the couple-level moderators as interpersonal perceptions can be biased (Gagne \& Lydon, 2004). Furthermore, both self- and partner-perceptions of responsiveness (Lemay, Clark, \& Feeney, 2007) and support (Schwarzer \& Knoll, 2007) were shown to help adjust to stress. In addition to our preregistered analyses, we ran post-hoc exploratory analyses investigating the role of the meaning and distress of the loss, shorter time intervals, and demographic moderators.

\section{Method}

\section{Procedure}

The data analyzed here are from the [blinded] study, a multi-wave longitudinal online study of romantic couples conducted at [blinded] between 2016 and 2018. The primary purpose of the study was to investigate the associations between personality and romantic relationship outcomes. Participants were recruited from the student population, the local community, and via Facebook advertisements targeted at residents of Switzerland, Germany, and Austria who reported being in a relationship. Eligibility to participate was dependent on being at least 18 years old, having a partner who was at least 18 years old and who was also willing to participate, having a relationship duration of at least a month, and being able to respond to surveys in German.

The study consisted of four waves. Each wave included 14 days of online daily surveys with an additional battery of surveys on day 1 and day 14 . Waves 1 to 2 and 2 to 3 were separated by an interval of about six months; waves three and four by an interval of about 12 months. Participants entered wave 1 in one of 12 monthly cohorts. In subsequent 
waves participants were permitted to move to a different cohort (if their partner also moved) or to skip a wave if they were unable to participate at the scheduled time. Participants were permitted to participate as singles if their initial relationship ended, and new partners were invited to join the study. Participants were compensated with a shopping or cinema voucher to the value of 20 EUR per wave if they completed the extensive surveys on days 1 and 14 and at least seven of the 14 daily surveys. Participants also received personalized feedback on a selected measure if they requested it. Ethical approval for the study was granted by the ethics committee of the Department of Psychology at the [blinded]. For the present study, we used data from Wave 1 for the pre-event assessment (hereafter, Time 1) and data from Wave 4 (hereafter, Time 2) for the post-event assessment (Time 1 and 2 were on average 20.36 months apart in our subsample used in this paper, $S D=2.02$ (range 17-28). ${ }^{1}$

\section{Participants}

A total of 1,313 couples were recruited, with each consenting for surveys to be emailed to both partners. During the study, 10 new partners began participating. Three participants asked that their data be deleted, and a further 437 participants (belonging to 272 couples) withdrew (explicitly requested to discontinue participation). A detailed description of the full sample can be found in previous articles based on the same dataset [blinded]. The latter two articles used different variables than our study and the former used similar variables, but the focus of the study was different (on the reciprocal relationships between relationship characteristics and interpersonal vulnerabilities, of which self-esteem was one element).

A total of $n=1,238$ participants ( $n=619$ couples) provided data that could be analyzed in this study. We included participants from the full sample of $N=2,341$ based on the following criteria (those who were excluded successively are parenthesized): couples of whom at least 1 partner provided data on whether they experienced bereavement in the study 
period or not (for $n=941$ individuals both partners were missing this data, the full information maximum likelihood approach (FIML) cannot estimate the experience of this random event), male-female couples that were together at both Time 1 and 2 (necessary to test our hypotheses in APIMs; separation $n=76$, new partners $n=5$, participants without partners in the data set $n=7$, individuals from same-sex couples: $n=40$, missing gender information $=$ $3)$, and couples that report a bereavement between Time 1 and $2(n=31$ participants or their partners reported a bereavement in the same month when Time 1 or Time 2 took place and hence could neither be clearly assigned a 0 or 1 on the bereavement variable; those who reported a bereavement in early 2016 before T1 already met the other exclusion criteria). Those included and excluded participants from the full sample did not differ in any of the study variables (see Appendix A).

The mean age of participants at Time 1 was 31.97 years $(S D=13.26$; range $18-81)$. The average relationship duration was 8.16 years $(S D=10.02$; range $=2$ months -52.08 years). Participants reported their marital status using options from the Swiss census: $61.8 \%$ of the sample were single, 33.3 were married, $1.1 \%$ in a registered partnership, $3.1 \%$ divorced, $0.2 \%$ separated, and 0.6 widowed. $27.6 \%$ of the participants reported that they had children. A detailed overview of the education and income categories are shown in Appendix B. Of the $N=1,022$ participants in our sample, $n=216$ reported a bereavement between Times 1 and 2. Of those, $n=134$ lost a close relative (i.e., parents), $n=33$ a close friend, and $n=49$ others (e.g., grandparents, parents of the partner; see Appendix $\mathrm{C}$ for the reported relationships). Of the total number of 619 couples, $n=169$ reported a bereavement. In $n=$ 122 of these couples, only one partner reported a bereavement and in $n=47$ couples both partners reported a bereavement, of which $n=33$ reported the same bereavement date.

The preregistration, the instruments, an example of the $\mathrm{R}$ code of the data analysis, and the SPSS syntax of the formation of the variables can be found on the Open Science 
Framework, OSF (https://osf.io/a39jv/?view_only=146911aa2bc0428c9ebe81df7b9ab19f).

Given that we share data for scientific purposes only and given that we want to ensure that no person (or partner) is identified in the data set, we share a minimal dataset including the data for this study upon publication on [blinded]. After registration, data can be accessed by employees of research institutions. This procedure follows the recommendations for sharing couple data (Joel, Eastwick, \& Finkel, 2018).

\section{Measures}

\section{Self-Esteem}

Self-esteem was measured at Time 1 and 2 with the German version of the Rosenberg Self-Esteem Scale (Rosenberg, 1965; von Collani \& Herzberg, 2003). Participants rated 10 items on a 4-point Likert scale ranging from 1 (strongly disagree) to 4 (strongly agree). An example item is "On the whole, I am satisfied with myself." At Time 1, participants filled in this questionnaire twice (at the first and last day of the daily diary period). Both scores correlated highly: $r=.87$ ). We averaged them for Time 1, which had the benefit of decreasing the number of missing values. The internal consistency as indicated by Cronbach's alphas were at Time 1.89 at day 1 and .92 at day 14 and at Time 2 it was .91.

\section{Life Satisfaction}

Life satisfaction was measured at Time 1 and 2 with the German version of the Satisfaction with Life Scale (Diener, Emmons, Larsen, \& Griffin, 1985; Glaesmer, Grande, Braehler, \& Roth, 2011). Participants rated 5 items on a 5-point Likert scale ranging from 1 (strongly disagree) to 5 (strongly agree). An example item is "In most ways my life is close to my ideal." As for self-esteem, we averaged the life satisfaction score from the first and last day of the daily diary period at T1 $(r=.83)$. The Cronbach's alphas were at Time 1.83 at day 1 and .85 at day 14 and at $\mathrm{T} 2.86$.

\section{Bereavement}


At Time 2, participants were asked about various life events, including bereavement: "Has a person (other than your partner) who was close to you passed away since the beginning of 2016"? The first cohort started the study in March 2016. If individuals lost more than one person, they were asked to report on the most serious loss. If participants indicated "yes", they were asked in which year and month the bereavement occurred. We formed a dummy-coded bereavement variable on the individual level. Participants received a 1 on this variable if they reported a bereavement that happened after T1 and before $\mathrm{T} 2$ (as for them we have a pre- and post-event assessment that allows us to examine change). Everyone else received a 0 on that variable.

\section{Type of Lost Relationship}

Participants who indicated having lost someone were asked: "How was the deceased person related to you?" Participants could choose from a list of people (child, close relative (e.g., parent), close friend, and others). When indicated "other", participants could report in an open response format on the type of the lost relationship (see Appendix C). We formed a dichotomous variable by using the original "close relative" category $(n=134)$ and by collapsing "close friend" and "others" in the "others" category $(n=82)$.

\section{Romantic Relationship Characteristics}

Four relationship characteristics were assessed daily during the 14-day diary phases at each of the two time points: social support, self-disclosure, responsiveness, and closeness. For the main analyses, we use the assessments of $\mathrm{T} 1$ (at the same time as the pre-event assessment of self-esteem and life satisfaction), as this represents the relationship resource that was available to the couple before the bereavement. Both partners of a couple reported about their daily couple interactions with respect to these characteristics. Many provisions of support reported by supporters are unnoticed by the recipient (i.e., invisible support) but have been found to help with adjustment to stress (Bolger, Zuckerman, \& Kessler, 2000). For social 
support, self-disclosure, and responsiveness, we therefore assessed both self- and partnerreports (i.e., both partners reported on themselves and their partner).

For each construct, we averaged the 14 daily experiences to obtain an indicator for the average daily experiences at T1. Specifically, we first averaged the same item that was assessed each day of the 14-daily diary period and then averaged these averaged items of the same scale (i.e., for which the reliability indicators are presented below). We aggregated the self- and partner-reports from both partners per construct to obtain a more accurate estimate of the relationship characteristics than can be achieved by a sole reliance on self-reports. For social support, for example, we formed an average score for one partner based on the selfreported "received support" score and the partner-reported "enacted support" score to get a more objective indicator of how much social support this partner had). Appendix D shows the correlations between the self- and partner-reports of both partners per construct. The correlation of the scores of both partners was high: $r=.78, p<.001$ for responsivenesscloseness, $r=.89, p<.001$ for self-disclosure, $r=.81, p<.001$ for support.

Social Support. Social support was assessed using 4 items (Shrout, Hermann, \& Bolger, 2006): One item for emotional and one for practical support that a person received and one item for emotional and one for practical support that a person provided. To measure received support, participants were asked to indicate any help they had received with a worry, problem, or difficulty from their partner each day with a yes / no format. Help could be emotional (e.g., listening, comforting; "My partner provided emotional support to me today.") or practical (e.g., doing something concrete; "My partner provided practical support to me today."). Corresponding items were used to ask participants if they had provided emotional or practical support to their partner. The correlations at T1/T2 of the two received support items were $r=.62 / .60$, of the two provided support items they were $r=.62 / .65$.

\section{Responsiveness and Closeness.}


Responsiveness. Participants rated responsiveness using 4 items for enacted responsiveness and 4 corresponding items for perceived responsiveness (Laurenceau et al., 2005). An example item for enacted responsiveness is "How much have you understood your partner today?", and the corresponding example item for perceived responsiveness is "Today I felt understood by my partner". The items were rated on a 5-point Likert scale, ranging from 1 (very little) to 5 (a great deal). We rescaled this scale to a 7-point scale to form the composite score. The Cronbach's alphas for T1 / T2 for perceived responsiveness were .94 / .94 and for enacted responsiveness they were $.91 / .91$.

Closeness. Participants rated the closeness they felt to their partner using 4 items (Schoebi et al., 2012). An example item is "To what extent did you feel close to your partner today?". The items were rated on a 7-point Likert scale, ranging from 1 (hardly) to 7 (very much). The Cronbach's alphas for T1 / T2 were .97 / .97.

We formed a composite score of the closeness scale and the responsiveness scale (henceforth called responsiveness). The decision for a composite score was based on a very high correlation between the two scales ( $r=.91$ for self-reported responsiveness and closeness) and on the conceptual overlap between the items of the scales (Two of the four items of the responsiveness scale were: “Today I felt understood by my partner." and "Today I felt validated by my partner.", which were very similar to one of the four items of the closeness scale "To what extent did you feel understood and validated by your partner today?").

Self-Disclosure. Participants rated their own and their partner's self-disclosing behavior using 3 items for enacted self-disclosure and 3 corresponding items for partner selfdisclosure (Laurenceau et al., 2005). An example item for enacted self-disclosure is: "Today, I have disclosed my thoughts to my partner." and the corresponding example item for partner self-disclosure is: "Today, my partner disclosed his/her thoughts to me." Items were rated on 
a 5-point Likert scale, ranging from 1 (very little) to 5 (a great deal). The Cronbach's alphas for T1 / T2 for enacted self-disclosure were .89 / .92 and for partner self-disclosure .90/.93. Age

Age was assessed in years and used as a covariate. Given that the couple members' ages were highly correlated $(r=.96)$, we used the mean couple age as a control variable to avoid adding two variables that showed high multicollinearity.

\section{Analytic Strategy}

We conducted actor-partner interdependence models (APIMs; Kenny, Kashy, \& Cook, 2006) to capture the actor and partner effects of bereavement on levels and changes in selfesteem and life satisfaction (Hypotheses 1 and 2, respectively; the preregistered analysis plan is available on the OSF). We applied path models to test whether the intrapersonal effects vary depending on the type of lost relationship (close relative versus friends and others; Hypothesis 3) and we applied moderated APIMs to test whether the actor and partner effects vary depending on three relationship characteristics (Hypothesis 4). For that purpose, we used the lavaan package (Rosseel, 2012) in R (R Development Core Team, 2016) and handled missing data with the FIML approach (e.g., Enders, 2001).

Before testing our hypotheses, we examined, as pre-registered, potential differences between individuals who have experienced a bereavement during the study compared to individuals who have not. These differences are tested for age, relationship duration, living together, education, and having children. If potential differences arise, we will control for such differences in the analytic models. In all models, we accounted for the couple's average age, and the time between the two assessments (number of months between T1 and T2), as the time varied somewhat between couples (for the model, see Figure 1).

To test Hypotheses 1 and 2, we predicted changes in self-esteem and life satisfaction in both partners from their bereavement status ( 0 or 1$)$. We used a residualized approach that 
predicts variability in individuals' T2 levels (post-bereavement levels for the bereaved) and is often used as an index of personality change (Krueger, 1999; for recent studies using this approach; see Chopik, 2018; Luciano \& Orth, 2017)². We controlled for both partners' T1 baseline (which was, for the bereaved, the pre-event assessment) levels of self-esteem or life satisfaction, respectively. Note that in some couples, no bereavement had been experienced $\left(n_{\text {couples }}=450\right)$, in some couples one partner had experienced a bereavement $\left(n_{\text {couples }}=122\right)$, and in other couples both partners had experienced a bereavement $\left(n_{\text {couples }}=47\right)$. We collapsed the couples in which one and those in which both partners experienced a bereavement in the group of "the bereaved"; the sample size did not allow to examine them separately. This is justified conceptually based on the assumption that partners can be impacted by bereavement via both direct and indirect paths. For the descriptive statistics of both types of couples at T2 see Appendix F.

To test Hypothesis 3, we computed path models including all persons who reported a bereavement and predicted their self-esteem or life satisfaction levels and change by their initial self-esteem or life satisfaction levels, respectively; an interaction term with previous self-esteem or life satisfaction levels and the type of the lost relationship; and the main effect of the type of the lost relationship. ${ }^{3}$ For Hypothesis 4, we computed moderated actor-partner interdependence models including all participants (bereaved and non-bereaved), and added a relationship characteristic (e.g., responsiveness) and an interaction term bereavement $x$ responsiveness for each partner to the actor-partner interdependence model to predict both partners' self-esteem and life satisfaction, respectively.

Goodness of fit of the APIMs and path models was assessed with the comparative fix index (CFI), the root mean square error of approximation (RMSEA), and the standardized root mean square residual (SRMR). A model is considered to have an acceptable fit if CFI is above .95, RMSEA below .08, and SRMR below .10 (Schermelleh-Engel, Moosbrugger, \& 
Müller, 2003). For the APIMs, we treated partners as distinguishable based on their gender. Nested model comparison was used to examine whether constraining actor and partner effects to be equal across female and male partners did not fit the data significantly worse compared to freely estimating these effects. A non-significant chi-square difference test would be indicative that the constrained model fits the data equally well as the less constrained model. However, given that chi-square difference tests are sensitive to sample size, we additionally considered the test of small difference in fit in cases when the chi-square difference test was significant (MacCallum, Browne, \& Cai, 2006). For the regression analyses, we standardized all continuous predictor variables using the means and standard deviations of the full [blinded] sample at the respective wave (for a similar approach, see van Scheppingen, Chopik, Bleidorn, \& Denissen, 2019). The obtained standardized confidence intervals can be interpreted as the range of possible standardized effect sizes in the population.

\section{Power Analysis}

Most previous studies on self-esteem and life satisfaction found small-to-medium negative effects of negative life events (e.g., Luhmann et al., 2012 [for life satisfaction and divorce, a meta-analyzed effect size of $b=-.07$, for life satisfaction and bereavement, a metaanalyzed effect size of $b=-.48$ ]; Orth et al., 2009 [for self-esteem and stressful life events, effect sizes ranged between $b=-.01$ and -.21 across three studies) and for spousal or child loss they ranged between -.09 and -.19 (e.g., Bratt et al., 2017 [for life satisfaction, $\beta$ s ranged between -.14 and -.19]; Luhmann et al., 2012; Wonch Hill et al., 2017 [for self-esteem, $b$ s ranged between -.09 and -.19]). For the present study, we anticipate somewhat lower effect sizes as we study comparatively less close relationship partners. Evidence is scarce but a recent study has revealed an unstandardized regression coefficient of friend loss of .11 for life satisfaction after 10-12 months (Liu et al., 2019). Effects of parental loss ranged between $b=$ -.11 for life satisfaction one year after parent's death ([mother's death: -.14; father's death: - 
.10] Leopold \& Lechner, 2015) and $b=.02$ for self-esteem (this effect was, however, similar in size to the effect of unemployment, which usually has larger effects, so the study possibly underestimated life event effects; Tetzner et al., 2016).

We conducted sensitivity analyses with two different tools: the APIM power by Ackerman \& Kenny (2016) for the dyadic models and G*Power (Faul, Erdfelder, Lang, \& Buchner, 2007) for the path regression models. As we did not have specific information, we used rough estimates from related research to make assumptions about the correlation of bereavement between partners (.30/.15) (no available data) and the correlation of the error terms of their outcome variables (.20/.10; ranging for life satisfaction and self-esteem between $b=.11$ and .20; Orth, Erol, Ledermann, \& Grob, 2018). The smallest actor and partner effect that could be detected with adequate power (.80) using a sample of 619 couples were .079 and .080 , respectively. The analyses for the path regression analyses with a sample of 216 bereaved individuals, five predictors, and a power of .80 yielded a detectable effect size of $f^{2}$ $=.06$.

To establish the power for the moderation analyses, we drew from previous studies on the interaction effect of support (for which there exists more research than for the other characteristics) and negative life events, stress, or bereavement (many bereavement studies did not report betas). These studies reported beta coefficients ranging from .01 to .43 (average .20; Brosseau et al., 2011; Mairean, 2016; Raffaelli et al., 2013; Shi, 2021; Stroebe et al., 2005). The power analysis for the dyadic models suggested that this range is covered with a power between .06 and $>.99$, with the mean effect of .20 being detectable with a power of $>$.99. The corresponding power analysis for the path models for effect sizes of $f^{2}=.06$ and .48 yielded power between .79 and $>.99$, with the mean effect of $f^{2}=.25$ being detectable with a power of $>.99$ (for conversion guidelines from beta to r, see Peterson \& Brown, 2005). However, given that interaction effects are generally smaller than those reported in previous 
studies on support (median $f^{2}=.002$; for a review, see Aguinis et al., 2005), it is likely that the effect sizes for the present study are on the lower bound of the expected effect-size range. Hence, our moderation analyses might be weakly powered to detect small interaction effects. Nevertheless, we conduct the moderation analyses as pre-registered to provide authors of future dyadic bereavement studies with an indication of the effect sizes. We are, however, cautious in the interpretation of the results of the moderation analyses.

\section{Results}

\section{Descriptive Statistics}

The bivariate correlations, means, and standard deviations for bereaved and nonbereaved individuals can be found in Table 1 (for the bivariate correlations for female and male partners see Appendix E). Before conducting the main analysis, we first examined whether those who experienced a bereavement differed from those who did not. We conducted independent-sample t-tests and chi-square tests on the T1 demographic and study variables. We did not find any group differences in any demographic or study variable (see Appendix F). We therefore did not include any covariates in our analyses except for age because age has been found to be linked to the effect of bereavement on psychological wellbeing (Infurna et al., 2017; Luhmann et al., 2012; Moor \& de Graaf, 2016).

\section{Actor and Partner Effects of Bereavement on Self-Esteem and Life Satisfaction}

The model fits for the preregistered analyses can be found in Appendix G. All actor and partner effects could be set equal across couple members for the following APIMs and moderated analyses. Table 2 displays the results of the APIMs predicting the level at T2 in self-esteem or life satisfaction as a function of the bereavement experience, while accounting for the T1 level of self-esteem or life satisfaction, time interval between $\mathrm{T} 1$ and $\mathrm{T} 2$, and the couple's average age. Bereavement did not significantly predict self-esteem level, self-esteem change, life satisfaction level, or life satisfaction change - neither on the actor nor on the 
partner level. In contrast to Hypotheses 1 and 2, these results suggest that bereavement did not predict self-esteem or life satisfaction in the individual who reported the bereavement, or in their partner. ${ }^{4}$

\section{Moderation Analyses}

Table 3 shows the results of the moderation analyses for the type of lost relationship. To test Hypothesis 3, we examined whether the type of the lost relationship (i.e., a close family member versus friends or others) moderated the stability effect of self-esteem and life satisfaction levels at T1 on their levels and change at T2. Whether or not the deceased person of the bereaved participant was a close family member did not change the non-significant effect between bereavement and self-esteem or life satisfaction.

Tables 4, 5, and 6 show the results of the moderation analyses for the relationship characteristics (i.e., social support, responsiveness-closeness, and self-disclosure) for our testing of Hypothesis 4. We tested whether they moderated the link between bereavement and self-esteem or life satisfaction. The couple's social support, responsiveness, and selfdisclosure did not moderate the effect of bereavement on later self-esteem or life satisfaction. These results suggest that relationship characteristics, as reported by both partners, neither buffer nor exacerbate the effect of bereavement on later self-esteem and life satisfaction.

\section{Additional Analyses}

We conducted several post-hoc analyses to explore potential reasons for the absence of our hypothesized negative effect of bereavement on self-esteem and life satisfaction.

\section{Subjective Meaning of the Bereavement}

We suspected that the bereavement event could have been experienced differently, that for some it may not be an entirely negative experience. We explored this post-hoc hypothesis as follows. Bereaved participants were asked to report the meaning of the bereavement with the following question: "What meaning did this loss have for you?", which 
participants answered on a 5-point Likert scale ranging from 1 (very negative) to 5 (very positive). Of the 216 bereaved persons, one person rated the bereavement experience as very positive, 4 persons rated it as positive, 46 rated it as neutral, 97 rated it as negative, and 68 rated it as very negative. First, we explored differences between those who rated it as negative $(n=165)$ and those who rated it as positive or neutral $(n=51)$ and found no group differences in the study or demographic variable, except for age, as participants who rated the bereavement as positive/neutral were significantly older than those who rated it as negative (see Appendix H).

Next, we explored whether the meaning of the bereavement (negative versus positive/neutral) predicted self-esteem and life satisfaction in bereaved individuals, and whether it moderated the stability effect of earlier levels on later self-esteem and life satisfaction levels and change. No significant interaction effects were found (all $p>.20$ ). We found, however, that the bereavement meaning predicted self-esteem level $(b=.17,95 \% \mathrm{CI}=$ $[.08, .25], p<.001)$ and change $(b=.17,95 \% \mathrm{CI}=[.09, .26], p<.001)$ : having a positive/neutral (versus negative) meaning was related to higher self-esteem levels and more positive self-esteem changes. The meaning of the bereavement event did not predict life satisfaction level and change (all $p>.21$, see Appendix I).

Next, we ran independent $t$-tests between the groups (i.e., no bereavement, negative bereavement, positive/neutral bereavement). We found differences in self-esteem change between the bereaved group with a negative meaning and the bereaved group with a positive/neutral meaning $(t[212]=-3.04, p=.003)$; we found no differences in their later selfesteem levels (all $p s>.05$ ). As can be seen in Figure 2, bereaved individuals who rated the event as positive/neutral experienced on average slight increases in self-esteem $(M=.15$, $t[49]=3.78, p<.001)$, as did the non-bereaved individuals $(M=.05, t[883]=3.49, p<.001)$ while bereaved individuals who rated the event as negative experienced on average no 
significant self-esteem change $(M=-.02, t[163]=-.61, p=.55)$. No significant differences in their life satisfaction levels and changes were found between the three groups (all $p \mathrm{~s}>.05$ ).

Our hypotheses were based on the assumption that bereavement is a negative event. However, our analyses showed that bereavement did not have a negative meaning for $24 \%$ of the bereaved individuals in our sample, which makes a general negative effect of bereavement on self-esteem and life satisfaction less plausible. To test whether a bereavement that was experienced as a negative event had a negative effect on self-esteem and life satisfaction, we repeated the main analyses (i.e., [moderated] actor-partner interdependence models and moderated path models) but excluded the 51 individuals and their partners who experienced the bereavement as positive/neutral, excluding 45 couples in the (moderated) APIMs. For these analyses, we used a sample of 574 couples, the lowest adequately powered actor and partner effects have the effect size of .081 with higher between-partner correlations ( .30 and $.40)$ and .082 with lower between-partner correlations (.15 and .20). Appendix J displays the model fits to these respective analyses, and Tables K1 through K5 (see Appendix K) show the model results. Two significant effects emerged: In the APIM that tested bereavement as a predictor of self-esteem level and in the APIM that tested bereavement as a predictor of selfesteem change, we found a significant partner effect: If the actor experienced a negative bereavement event, it predicted lower self-esteem levels and negative change in the partner.

We also repeated the moderator analyses without participants (and their partners) who experienced a bereavement that was perceived as positive or neutral. Again, the relationship to the deceased person (i.e., close family members versus others) did not act as a significant moderator. In other words, the type of relationship with the deceased person neither buffered nor exacerbated the effect of bereavement on later self-esteem and life satisfaction levels and change. Similarly, the relationship characteristics (i.e., social support, responsiveness, and self-disclosure) did also not act as significant moderators. 


\section{Distress of the Loss as Moderator}

We explored whether the experienced distress of the loss moderated the effect of bereavement on the stability paths in the bereaved sample. Participants rated their agreement to the items "Independent of whether you experienced this event as positive, neutral, or negative: If you think back, how distressing was this loss for you at that time?" and "And how distressing is this loss for you today?" on a scale ranging from 0 (not at all) to 10 (very much). Moderation analyses showed that neither the distress of the loss experienced at the time of the bereavement, nor the distress experienced at T2 acted as significant moderators of the stability effects in self-esteem and life satisfaction (Appendix L; Tables L1 and L2). We found, however, a main effect of distress of the loss that was experienced at $\mathrm{T} 2$ and life satisfaction levels at $\mathrm{T} 2$ and change in life satisfaction between $\mathrm{T} 1$ and $\mathrm{T} 2$. These results indicate that the distress experienced from bereavement at T2 was also negatively linked to participants' life satisfaction at the same time point and the change in life satisfaction up to that time point. Distress of the loss significantly decreased over time (distress at time of event: $M=6.82$; distress at T2: $M=4.24 ; t[214]=18.76, p<.001)$.

\section{Did the Bereavement Effects Fade over Time?}

Previous research has shown that the negative impact of bereavement decreases with years after loss (e.g., Spahni et al., 2016) but there are also reports of no effects of time after loss (Pohlkamp, Kreicbergs, \& Sveen, 2019). To examine whether the effect of bereavement on self-esteem and life satisfaction changed over time, we conducted two post-hoc analyses. First, we explored whether the time since the bereavement acted as a significant moderator in the group of bereaved individuals. To that end, we created a variable that measures the number of months between the bereavement event and the post-event assessment at $\mathrm{T} 2$ and examined its direct effect in the outcome variables, but also its moderating effect on the 
stability effect. The bereavement event and the post-event assessment at $\mathrm{T} 2$ were on average 10.19 months $(S D=6.19)$ apart $($ range $0-22) . .^{5}$

As shown in Appendix M, the time to post-event assessment did neither exert a main effect on self-esteem, nor did it moderate the stability effects of self-esteem among bereaved individuals. We found, however, a main effect of time to post-event assessment and an interaction effect for life satisfaction levels and changes at T2. As for the main effect, the longer the time distance between the bereavement event and the post-event assessment, the higher the life satisfaction levels and the more positive the life satisfaction changes in bereaved individuals. As for the interaction effect, a median split with time to post-event assessment revealed that those participants for whom the time to post-event assessment was longer $(n=105)$ showed lower stability in life satisfaction $(r=.69)$ compared to those with shorter time to post-event assessment $(n=111, r=.83, z=2.34, p=.01)$.

Second, we examined whether a shorter measurement interval would reveal a different result from our main analyses (for which we used Wave 4 as post-event assessments for the reasons explained above). For these post-hoc analyses, we used the closest post-event assessments for each bereaved individual (for example, if the bereavement occurred between W1 and W2, we used W2, if it occurred during W2, we used W3). The average time for all participants between the pre-event assessment at T1 (W1) and the post-event assessment was 14.66 months $(S D=6.90)^{4}$. The average time from the bereavement event to the post-event assessment was 4.55 months $(S D=3.40)$. We ran path models with all individuals $(N=$ 1,238) included in the current study and tested whether bereavement predicted later selfesteem and life satisfaction levels and change with tighter measurement intervals, controlling for levels at T1, the time interval between $\mathrm{T} 1$ and the closest post-event assessment, and the age of the individual. Because all individuals in these analyses were nested in dyads, we used the lavaan.survey package (Oberski, 2014) to estimate confidence intervals that are adjusted 
for the nested data structure. The results showed that bereavement remained a non-significant predictor of self-esteem and life satisfaction levels and change (see Appendix N).

Descriptive results showed that for bereaved individuals who rated the event as neutral or positive, self-esteem increased during these shorter intervals $(M=.14, t[47]=3.61, p$ $<.001)$. Self-esteem also slightly increased for non-bereaved individuals $(M=.04, t[897]=$ $3.28, p=.001$ ), while it did not change in bereaved individuals who rated the event as negative $(M=.00, t[160]=.10, p=.92)$. Significant group differences were found between the two bereaved groups with positive/neutral and negative meaning $(t[207]=-2.53, p=$ .012). Figure 5 depicts the self-esteem changes with a narrower assessment interval. Regarding changes in life satisfaction, we found that bereaved individuals who rated the event as negative $(M=.11, t[149]=2.67, p=.009)$ and the non-bereaved individuals $(M=.14$, $t[840]=7.59, p<.001)$ increased in life satisfaction. The bereaved individuals who rated the event as positive or neutral $(n=51)$ did not significantly change in their life satisfaction $(M=$ $.13, t[46]=1.81, p=.08)$. However, no significant group differences emerged (all $p \mathrm{~s}>.05)$.

\section{Age as Moderator}

We also explored whether age moderated the effect between bereavement and selfesteem or life satisfaction. Previous research has reported mixed results, either that younger adults were faring worse than middle-aged or older adults after experiencing bereavement (Leopold \& Lechner, 2015; Spahni et al., 2016), that they were faring better than older adults (Bennett et al., 2019) or that both young and elderly adults were most vulnerable to repeated losses in their network (Infurna \& Mayer, 2019). We therefore explored linear and quadratic main and interaction effects for age (i.e., average couple age) as moderator. The results are presented in Appendix O. We did not find that age or age squared moderated the effect of bereavement on both partners in couples.

\section{Individual-Level Robustness Analyses}


To decrease the uncertainty about whether the dyadic models were underpowered, we examined the robustness of the results. In response to a reviewer's comment, we tested a set of simplified path models that had larger power. It allowed us to check if the missing actor and partner effects of bereavement and moderation effects of relationship characteristics (and age) were due to insufficient power. We restructured our data to a pairwise data set and tested path models with each person's outcome variable (i.e., self-esteem or life satisfaction level or change) predicted by their and their partner's previous levels of these variables and bereavements (and their and their partners' main and interaction terms for relationship characteristics or age/age squared, respectively). Thus, the data was not split into women and men, but every person represented an actor and a partner. We treated actor and partner effects as indistinguishable (i.e., equal) across female and male partners, which was justified by the results of the main analyses. To control for the nested data structure, the confidence intervals were adjusted by using the lavaan.survey package.

The results of these better powered, simplified analyses yielded the same results in terms of their significance levels as the dyadic main and post-hoc analyses. More specifically, bereavement did not yield actor or partner effects on self-esteem and life satisfaction, and the relationship characteristics did not moderate the effects of bereavement. In the sample of nonbereaved individuals and individuals that experienced a negative bereavement event, a significant partner effect of bereavement on self-esteem levels and change emerged (as in the dyadic analyses). And, as in our dyadic analyses, relationship characteristics did not moderate the effects of negative bereavement, nor did age moderate the effects. We reported the individual-level analyses in the Appendix P. In sum, these findings provided evidence for the robustness of the findings of the dyadic analyses.

\section{Discussion}


A large body of literature indicates that bereavement can impair mental and physical health. Not much is, however, known about the effects of losing someone other than the partner or a child, especially on non-clinical outcomes such as self-esteem and life satisfaction. Research has also to considerable individual variability in the direction, magnitude, and longevity of effects of bereavement (Stroebe et al., 2007). Most of this research has focused on the directly bereaved individual and disregarded their romantic partners, who experience the event alongside them. Romantic partners may not only be affected themselves (Luhmann et al., 2014), but they can also provide a major source of support in daily life and help one another to cope with bereavement (Cohen \& Wills, 1985; Holt-Lunstad, 2018). Previous research has, however, reported mixed results and is restricted by several aspects of their methodology. The present study is the first to examine the impact of a bereavement on self-esteem and life satisfaction on both members of romantic couples, and moderating effects of the type of the lost relationship and relationship characteristics. This research makes an important contribution to theoretical discussions in the literature on bereavement, life events, growth, and self-esteem and life-satisfaction, as discussed below.

\section{Bereavement Did not Affect Actors' Self-Esteem and Life Satisfaction}

Our analyses showed that losing a close family member or friend did not directly affect self-esteem and life satisfaction. There are several potential explanations for the lack of an effect, some of which we examined in post-hoc analyses. First, it is possible that losing a family member or friend is not a disruptive life event for most people — at least not enough to impact their self-esteem and life satisfaction four months later. Recent research has suggested that the magnitude of changes in response to losing a family member or friend is smaller than for losing a child and partner (Infurna \& Mayer, 2019; Infurna et al., 2017). A few other studies have also found no effects of bereavement, including a study on bereaved individuals of which $80 \%$ lost friends (Murrell et al., 1991), and a study on self-esteem that examined 
parental loss (Tetzner et al., 2016), and one on personality and widowhood (Chopik, 2018). If replicated, this research may point to bereavement not having an average effect on self-esteem and life satisfaction, possibly because it does not diminish general feelings of social inclusion and conceptions of the world being an orderly place. Future research should examine whether negative life events outside of people's control have weaker effects as they are not tied to success or failure (James, 1890).

Still, some studies reported small negative effects of losing family members (Leopold \& Lechner, 2015) and friends (Liu et al., 2019) on life satisfaction. More research that examines and compares the magnitudes of the effects of losses of different types of relationships such as different types of family members and friends is needed before conclusions can be drawn. Ideally, given that it is a possibility that losing family and friends does not impact the development of self-esteem and life satisfaction, future studies will preregister to increase the likelihood that non-significant findings are also reported. If the nonsignificant effects for losing family members, friends, and others are replicated, this will inform the bereavement literature: the impact of bereavement might vary considerably depending on what type of relationship is lost, to the degree that it may not matter for a person's self-esteem and life-satisfaction development. Replications will also inform theories on well-being. A non-significant finding is in line with setpoint theory but given that longterm effects of widowhood on life-satisfaction have been found, a more likely explanation is that only losing core relationships has a lasting impact (Lucas, 2007).

Second, it is possible that the study period missed a critical period of change. Given that the negative impact of bereavement on subjective well-being is typically strongest shortly after the death (Luhmann et al., 2012), we explored whether T2 was too late to capture a potential initial decline in self-esteem. We therefore ran the same analyses but used the closest post-bereavement assessment available for each individual, which reduced the average 
time between the bereavement and the T2 assessment from 10 to 4 and a half months. Bereavement remained a non-significant predictor of self-esteem and life satisfaction. There is still a possibility that we missed an earlier decline to which individuals had already adapted at T2 (Infurna \& Mayer, 2019). The absence of an effect even after our shorter interval is, however, in line with previous studies on negative life events that reported only small or no effects (Mangelsdorf et al., 2019; Tetzner et al., 2016). Taking these findings together, it is not very likely that we would have found a significant decline in self-esteem and life satisfaction within four months after the event, but future research with higher temporal resolution (i.e., month-by-month) right after the loss is needed to corroborate this claim. Other interesting findings with respect to the role of time since the event in our study was that the more time had passed since the loss, the higher were the life satisfaction levels and the more positive were the life satisfaction changes. In addition, bereaved individuals for whom more time has passed since the loss had lower stability in life satisfaction. Together, these findings might be indicative of the beginning of a posttraumatic growth trajectory. Posttraumatic growth is a long-lasting process that becomes increasingly visible after overcoming the challenge (i.e., typically not within the first year after the event; Mangelsdorf et al., 2019; Tedeschi \& Calhoun, 2004). It is therefore worthwhile to extend the assessment interval. If positive long-term effects are found, this would inform the posttraumatic growth literature, as it would add bereavement due to losses of family members and friends to the list of events that can lead to posttraumatic growth.

\section{The Moderating Role of the Subjective Meaning of the Bereavement Experience}

An important consideration for our study and for future research is that individual differences in change might have been too large to lead to average effects (see Figures 3 and 4) - a finding that has also been reported for other life events, including self-esteem change during the transition to work (Reitz et al., 2020). The post-hoc analyses revealed several 
insights relevant for this explanation. Bereavement due to the death of a close person, a life event that is generally considered as a negative event (Keyes et al., 2014), did not have a negative meaning for everyone. In fact, for $24 \%$ of the sample the meaning was neutral or positive, which may have outweighed the already small negative effect for those for whom the meaning was negative. We therefore explored some differences between these groups to better understand individual differences in the experience of bereavement in our study.

An interesting finding was that the meaning of the bereavement event was linked to self-esteem levels and changes, in that a positive/neutral (versus negative) meaning was related to higher self-esteem levels and changes. Furthermore, we found that greater distress from bereavement reported at T2 was linked to less positive changes in life satisfaction. Supporting the claims of previous life event research (e.g., Luhmann, Fassbender, Alcock, \& Haehner, 2020), our findings underline the importance of accounting for the evaluation of the bereavement experience in order to understand individual differences in change in self-esteem and life satisfaction. The large variability in the meaning and degree of distress of the event, and the related variability in changes in the outcome variables might be one possible explanation for the contradictory findings of bereavement effects on self-esteem and life satisfaction discussed above (cf. the depression literature; Galatzer-Levy \& Bonanno, 2012). After all, self-esteem and life satisfaction capture the subjective evaluation of and experience of oneself and of life in general (Diener et al., 1985; Donnellan et al., 2012). Future life event research on self-esteem and life satisfaction should therefore account for the subjective experience of the life event.

Another interesting finding that extends existing research was that persons who reported a positive or neutral meaning of the bereavement showed an increase in self-esteem that was larger than for those who reported a negative bereavement (an increase is in line with the normative increase in self-esteem in adulthood; Orth et al., 2018). As the magnitude of 
increase of the non-bereavement group lay in between those for the positive/neutral and negative groups, it is therefore not surprising that no differences in the mean-level change between the bereaved and non-bereaved were found.

The greater increase in self-esteem change for the positive/neutral as compared to the negative meaning group should be interpreted with caution due to the relatively low sample size of the positive/neutral subgroup. Future research is needed to replicate the findings and to examine the factors that contribute to the above-than-normative increase in self-esteem for the positive/neutral subgroup. One potential explanation is that for those who reported a positive or neutral meaning, the bereavement was possibly accompanied by a lifted burden after caring for a relative, such as parent or grandparent, with a long-term illness (Langner \& Furstenberg, 2019). Although this is not very likely in our case as self-esteem at T1 was not significantly different between the positive/neutral subgroup and the negative subgroup, future research might consider the conditions of the death.

It is also possible that the larger increase in self-esteem change in the positive / neutral meaning subgroup compared to the negative meaning subgroup is indicative of posttraumatic growth. Posttraumatic growth in terms of more positive self-views has been observed in bereaved parents (Waugh et al., 2018). Together, these findings inform posttraumatic growth literature by supporting the proposition that posttraumatic growth can be framed as personality change by adding self-esteem to the list of characteristics for which growth is possible (Jayawickreme et al., 2020). An interesting line of future research is to examine the factors and processes that help this subgroup to increase in their self-esteem more than others. Given that the subjective meaning of the bereavement predicted self-esteem levels and change, a promising avenue for future research might be narrative identity. Narrative identity is considered to be an important mechanism for growth (McAdams \& Olson, 2010). It might be that those who ascribed a positive or neutral (versus negative) meaning to the bereavement 
event narrated the bereavement event in a positive light after revising their life story, which in turn, may have facilitated changes in self-esteem (Pasupathi, Mansour, \& Brubaker, 2007). It is also possible that those who found meaning in the loss increased in their emotion regulation skills, which might have facilitated increases in self-esteem (Cox \& McAdams, 2014). Future research might assess narratives about the bereavement to obtain a deeper insight into the processes of meaning making and its link to self-esteem change.

We explored whether the demographic variables used in this study were related to the meaning of bereavement. We found no support for a moderating effect of age on bereavement effects, which speaks against the effect of losses of different types of relationships being age graded. We did, however, find that those who reported a positive/neutral meaning were older than those who reported a negative meaning. This finding suggests that the meaning of bereavement is less negative for older than for younger adults. Future research should replicate this pattern (also for different relationship types), link it to other outcomes, and examine the age-related differences in the perceived meaning of bereavement in more detail. One reason for this finding might be that older adults are better at emotion regulation strategies, including focusing more attention to positive than to negative information and being more successful at using positive reappraisal (for a review, see Urry \& Gross, 2010). Another reason might be that the circumstances of deaths were more likely to evoke meaningmaking as the deceased might have been older, too, and hence, they might focus on thoughts such as "they have led a long life" or "they were released from long-term suffering".

\section{Bereavement Can Affect Partner's Self-Esteem}

Our analyses showed that people reacted to the bereavement experienced by their partners: when one couple member experienced a negative bereavement event, their partner had lower self-esteem levels and showed a decline in self-esteem. To the best of our knowledge, this is the first time that partner effects have been reported for bereavement. The 
findings extend the list of reported partner effects for other negative life events, too, including unemployment (life satisfaction; Luhmann et al., 2014), cancer (distress; Hagedoorn et al., 2008), and combat (PTSD; Renshaw et al., 2012). The findings are also in line with stress theories positing that stressful life events are dyadic phenomena that partners do not experience independently but as a couple (Bodenmann, 2005). As we found a partner effect when losing someone from the social network (which included weaker ties), it is likely that the partner effect would be even more prominent when losing stronger ties.

Interestingly, while the partner's self-esteem was affected by the loss, the bereaved person's self-esteem was not, which raises questions about the mechanisms at play. For unemployment, in contrast, the changes in life satisfaction in partners were less dramatic, which the authors attributed to some aspects of unemployment having unique effects on the unemployed actor only (e.g., boredom; Luhmann et al., 2014). Research on cancer responses has, however, also reported that partners often experience more psychological distress from the diagnosis than patients do (for a review, see Carlson, Bultz, Speca, \& Pierre, 2000). The authors discuss that a diagnosis comes with increased responsibilities and worry about the health of their sick partner. In line with this finding, partners' rather than individuals' chronic stress exposure was associated with increased blood pressure (Birditt, Newton, Cranford, \& Ryan, 2015). The authors speculate that spouses might feel obligated to support their partners under stress, while their own needs might not be met.

It is possible that a similar mechanism is at work when experiencing bereavement. As romantic partners are typically the primary coping resource to turn to in times of need (Samios \& Baran, 2018), it is possible that partners put the needs of their bereaved partners first and their own needs second. This focus on the partner's needs may negatively affect their self-esteem, while their partner's self-esteem is protected. Because the partner effect was only found for self-esteem but not for life satisfaction, it may be that sources specific to self- 
esteem are deprived when the partner is experiencing loss. Sociometer theory posits that a key source of self-esteem is social inclusion and perceptions of relational value (Leary \& Baumeister, 2000). As grief often entails social withdrawal (Miller, 2012), their partners might interpret that behavior as a sign of reduced own relational value. Hence, their basic need to belong might not be met, which may result in a decline in self-esteem. Examinations of this potential mechanism are needed in future research.

If replicated, the finding that individuals' self-esteem can be affected by their partner's bereavement experience has important novel implications for theory and clinical practice. Previous research on life events such as bereavement might have overlooked sources of stress as it has predominantly focused on individuals and not couples. A dyadic approach is needed to examine whether the pattern of our findings holds for other life events. Theories on personality and well-being development should provide a broader, more contextualized perspective that accounts for romantic partners to understand the impact of life events on selfesteem. A more contextualized perspective might also help develop efficient psychotherapies directed at couple's coping with an individual's bereavement. In sum, our findings suggest that both theory and practice might benefit from understanding romantic partners not as individuals, but as a system that responds to life events.

\section{No Moderation Effects of Type of Lost Relationship and Relationship Characteristics}

The type of the lost relationship did not buffer or exacerbate the effects of bereavement on self-esteem and life satisfaction. This is not very surprising as there is no significant main effect (the effect of the relationship types would have had to cancel each other out for a significant moderator effect). Nevertheless, it might be that, on average, a loss of a close family member simply does not impact self-esteem and life satisfaction differently than the loss of a close friend or other person. We based our prediction that the loss of a close family member has a stronger effect than friends and others on previous research reporting 
that child and spousal losses were most impactful (cf. Stroebe et al., 2007), because direct comparisons between other relationship types such as friends, first-degree relatives, and second-degree relatives are missing. However, some people might be closer to a friend than a parent or sibling. Future research might therefore assess the degree of experienced closeness with the deceased to directly test the assumption that the impact of the loss is greater when the relationship between the bereaved and the deceased is closer.

The romantic relationship characteristics did not moderate the effects of bereavement on self-esteem and life satisfaction, neither in the overall group nor among those who evaluated the meaning of the bereavement as negative. The bereavement effect might not have been "negative enough" to be buffered. Other research has, however, also not found consistent buffering effects of social support on psychological adjustment to bereavement (for a review, see Stroebe et al., 2007). A study on three longitudinal nationally representative samples found no evidence that social relationships established before widowhood buffered either reaction or adaptation to the death of a spouse (Anusic \& Lucas, 2013).

Against the backdrop of these previous findings, the beneficial impact of social support on personality and well-being to bereavement might be less straightforward as one might think. It might be related to the unique aspects of bereavement as a negative life event, as it entails a loss of a relationship that the partner cannot replace (Stroebe et al., 2007). It might also be that the loss creates stress when the partner might have to adjust to taking over roles previously filled by the person who died (Stroebe et al., 2005). Another potential reason for the mixed findings for social support is that unlike in our study, most previous studies that reported significant results used questionnaires and self-reports to assess support, which can increase the magnitude of effects due to shared method variance (Orth, 2013).

\section{Limitations and Future Directions}


The present study has several methodological strengths, including a longitudinal design with short-to-medium-term time frames (instead of several years), dyadic analyses of romantic couples, assessing couple characteristics using daily interactions and the meaning of and distress due to the bereavement, each of which have been recommended by other authors (Jayawickreme et al., 2020; Luhmann et al., 2014). But it also has limitations.

First, the power was not sufficient to detect very small actor and partner effects (the effect sizes we found for bereavement ranged between .00 and .04 on the actor level, and between .00 to .05 on the partner level) and small moderator effects (the size of the moderation effects we found ranged between .00 and .14 on the actor level and from .00 to .09 on the partner level). High-powered replication studies are needed to examine whether there are no effects or small ones that our study could not detect. From the effect sizes of the dyadic analyses and the robustness check using higher-powered individual-level analyses, we expect, however, that small effects are unlikely to be found in a higher-powered study.

Second, future well-powered research is needed to further examine the individual variability in change that we observed. In fact, researchers on bereavement might shift their focus from (potentially small) average effects to sources of heterogeneity. One source of heterogeneity that our findings suggested is the meaning that the bereaved ascribed to the loss (from very negative to very positive), which was linked to their change. Potential influences on meaning are individual (e.g., meaning making) and situational factors (e.g., circumstances of death: timely versus unexpected death; caregiver strain). In addition, larger samples are needed to examine the impact of losing specific types of relationships (e.g., parents, grandparents, friends) and of the relationship of both partners with the deceased (e.g., blood relatives versus in-laws, common friends versus friends of one partner). Larger samples are also needed to compare couples in which one or both partners report a bereavement. 
Third, the results might be limited in their generalizability. It is possible that the effect of bereavement was underestimated due to the sampling and inclusion criteria. Being in a stable, romantic relationship might have helped participants cope with the bereavement. Research has shown that individuals in romantic relationships had higher self-esteem and life satisfaction levels than singles (Dush \& Amato, 2005; Harris \& Orth, 2019) and that they were less negatively impacted after the loss of a parent (Hayslip, Pruett, \& Caballero, 2015). In addition, participants who were strongly impacted by a bereavement might have withdrawn or dropped out. Future studies therefore need to include a control group of singles.

Fourth, we cannot rule out that people had already experienced anticipatory change, such as in cases of long-lasting illness at T1 (Infurna et al., 2017; Wünsche, Weidmann, \& Grob, 2020), in which case we might have underestimated the impact of bereavement. It is possible that some participants were affected by previous losses that happened earlier than 3 months before the study. Large-scale panel studies are needed to account for the combined effect of repeated events and for anticipatory change in self-esteem and life satisfaction, as was recently done in a study on work transitions (Reitz, Luhmann, Bleidorn, \& Denissen, 2021). Studies with shorter time lags such as intensive longitudinal designs are needed to zoom in on the shorter timeline of change and to examine the relationship processes.

\section{Conclusion}

Humans are social animals and experience major life events alongside each other. Nevertheless, research on the impact of life events on personality and psychological wellbeing has traditionally only focused on individuals. Our study shows for the first time that an individual's negatively evaluated experience of bereavement due to the death of a close person (family member, friend, or others) predicts lower self-esteem levels and change in the romantic partner. Hence, individual reports of bereavement provide an incomplete picture of the factors influencing self-esteem change; instead, couples should be considered as a 
developmental unit. This finding emphasizes the need for a more contextualized approach that accounts for close relationships to study individual differences in change in personality and psychological well-being. Our study also demonstrates that a bereavement is not generally experienced as a negative life event — for some it can even be positive. The meaning that life events have for individuals, even if they are typically considered to be negative, provide valuable insights into individual differences in change in personality and psychological wellbeing. We hope this study stimulates other research that provides deeper insights into the contribution of the social environment and the unique experiences of stressful life events to individual differences in change in personality and psychological well-being. 


\section{Data-Accessibility Statement}

The study materials and analysis scripts used for this article can be accessed at https://osf.io/a39jv/?view_only=146911aa2bc0428c9ebe81df7b9ab19f. After registration, data can be accessed on FORSbase by employees of research institutions. This procedure follows the recommendations for sharing couple data (Joel et al., 2018). 


\section{References}

Ackerman, R. A., \& Kenny, D. A. (2016, December). APIMPower: An interactive tool for Actor-Partner Interdependence Model power analysis [Computer software]. Available from https://robert-a-ackerman.shinyapps.io/apimpower/

Albuquerque, S., Narciso, I., \& Pereira, M. (2018). Posttraumatic growth in bereaved parents: A multidimensional model of associated factors. Psychological Trauma: Theory, Research, Practice, and Policy, 10(2), 199-207. https://doi.org/10.1037/tra0000305

Anusic, I., \& Lucas, R. E. (2014). Do social relationships buffer the effects of widowhood? A prospective study of adaptation to the loss of a spouse. Journal of Personality, 82(5), 367-378. https://doi.org/10.1111/jopy.12067

Asselmann, E., \& Specht, J. (2020). Till death do us part: Transactions between losing one's spouse and the Big Five personality traits. Journal of Personality, 88(4), 659-675. https://doi.org/10.1111/jopy.12517

Baird, B. M., Lucas, R. E., \& Donnellan, M. B. (2010). Life satisfaction across the lifespan: Findings from two nationally representative panel studies. Social Indicators Research, 99(2), 183-203. doi: 10.1007/s11205-010-9584-9

Ballas, D., \& Dorling, D. (2007). Measuring the impact of major life events upon happiness. International Journal of Epidemiology, 36(6), 1244-1252. https://doi.org/10.1093/ije/dym182

Baltes, P. B. (1987). Theoretical propositions of life-span developmental psychology: On the dynamics between growth and decline. Developmental Psychology, 23(5), 611-626. https://doi.org/10.1037/0012-1649.23.5.611

Baltes, P. B., Lindenberger, U., \& Staudinger, U. M. (2006). Lifespan theory in developmental psychology. Handbook of Child Psychology, 1, 569-664. https://doi.org/10.1002/9780470147658.chpsy0111 
Bennett, K. M., Morselli, D., Spahni, S., \& Perrig-Chiello, P. (2019). Trajectories of resilience among widows: a latent transition model. Aging and Mental Health, 24(12), 1-8. https://doi.org/10.1080/13607863.2019.1647129

Bergstraesser, E., Inglin, S., Hornung, R., \& Landolt, M. A. (2015). Dyadic coping of parents after the death of a child. Death Studies, 39(3), 128-138.

https://doi.org/10.1080/07481187.2014.920434

Birditt, K. S., Newton, N. J., Cranford, J. A., \& Ryan, L. H. (2015). Stress and negative relationship quality among older couples: Implications for blood pressure. The Journals of Gerontology, Series B: Psychological Sciences and Social Sciences. doi:10.1093/ geronb/gbv023

Bleidorn, W., Buyukcan-Tetik, A., Schwaba, T., van Scheppingen, M. A., Denissen, J. J. A., \& Finkenauer, C. (2016). Stability and change in self-esteem during the transition to parenthood. Social Psychological and Personality Science, 7(6), 560-569. https://doi.org/10.1177/1948550616646428

Bodenmann, G. (2005). Dyadic Coping and Its Significance for Marital Functioning. In T. A. Revenson, K. Kayser, \& G. Bodenmann (Eds.), Decade of behavior. Couples coping with stress: Emerging perspectives on dyadic coping (p. 33-49). American Psychological Association. https://doi.org/10.1037/11031-002

Bolger, N., Davis, A., \& Rafaeli, E. (2003). Diary methods: Capturing life as it is lived. Annual Review of Psychology, 54(1), 579-616. https://doi.org/10.1146/annurev.psych.54.101601.145030

Bolger, N., Zuckerman, A., \& Kessler, R. C. (2000). Invisible support and adjustment to stress. Journal of Personality and Social Psychology, 79(6), 953-961. https://doi.org/10.1037/0022-3514.79.6.953

Bonanno, G. A., Lehman, D. R., Tweed, R. G., Haring, M., Wortman, C. B., Sonnega, J., 
Carr, D., \& Nesse, R. M. (2002). Resilience to loss and chronic grief: A prospective study from preloss to 18-months postloss. Journal of Personality and Social Psychology, 83(5), 1150-1164. https://doi.org/10.1037/0022-3514.83.5.1150

Bratt, A. S., Stenström, U., \& Rennemark, M. (2017). Effects on life satisfaction of older adults after child and spouse bereavement. Aging and Mental Health, 21(6), 602-608. https://doi.org/10.1080/13607863.2015.1135874

Breslau, N., Kessler, R. C., Chilcoat, H. D., Schultz, L. R., Davis, G. C., \& Andreski, P. (1998). Trauma and posttraumatic stress disorder in the community. Archives of General Psychiatry, 55(7), 626-632. https://doi.org/10.1001/archpsyc.55.7.626

Brosseau, D. C., McDonald, M. J., \& Stephen, J. E. (2011). The moderating effect of relationship quality on partner secondary traumatic stress among couples coping with cancer. Families, Systems and Health, 29(2), 114-126. https://doi.org/10.1037/a0024155

Burke, C. T., Shrout, P. E., \& Bolger, N. (2007). Individual differences in adjustment to spousal loss: A nonlinear mixed model analysis. International Journal of Behavioral Development, 31(4), 405-415. https://doi.org/10.1177/0165025407077758

Callan, M. J., Kay, A. C., \& Dawtry, R. J. (2014). Making sense of misfortune: Deservingness, self-esteem, and patterns of self-defeat. Journal of Personality and Social Psychology, 107(1), 142-162. http://dx.doi.org/10.1037/a0036640

Carlson, L. E., Bultz, B. D., Speca, M., \& St. Pierre, M. (2000). Partners of cancer patients: Part I. Impact, adjustment, and coping across the illness trajectory. Journal of Psychosocial Oncology, 18(2), 39-63. https://doi.org/10.1300/J077v18n02_03

Carr, D. (2004). Gender, preloss marital dependence, and older adults' adjustment to widowhood. Journal of Marriage and Family, 66(1), 220-235. https://doi.org/10.1111/j.0022-2445.2004.00016.x

Chopik, W. J. (2018). Does personality change following spousal bereavement? Journal of 
Research in Personality, 72, 10-21. https://doi.org/10.1016/j.jrp.2016.08.010

Clark, M. S., \& Lemay, E. P., Jr. (2010). Close relationships. In S. T. Fiske, D. T. Gilbert, \& G. Lindzey (Eds.), Handbook of social psychology (p. 898-940). John Wiley \& Sons, Inc. https://doi.org/10.1002/9780470561119.socpsy002025

Cohen, S., \& Wills, T. A. (1985). Stress, social support, and the buffering hypothesis. Psychological Bulletin, 98(2), 310-357. https://doi.org/10.1037/0033-2909.98.2.310

Cox, K., \& McAdams, D. P. (2014). Meaning making during high and low point life story episodes predicts emotion regulation two years later: How the past informs the future. Journal of Research in Personality, 50, 66-70. https://doi.org/10.1016/j.jrp.2014.03.004

Denissen, J. J. A., Luhmann, M., Chung, J. M., \& Bleidorn, W. (2019). Transactions between life events and personality traits across the adult lifespan. Journal of Personality and Social Psychology, 116(4), 612-633. https://doi.org/10.1037/pspp0000196

Diener, E., \& Chan, M. Y. (2011). Happy people live longer: Subjective well-being contributes to health and longevity. Applied Psychology: Health and Well-Being, 3(1), 143 https://doi.org/10.1111/j.1758-0854.2010.01045.x

Diener, E. D., Emmons, R. A., Larsen, R. J., \& Griffin, S. (1985). The satisfaction with life scale. Journal of Personality Assessment, 49(1), 71-75. https://doi.org/10.1207/s15327752jpa4901_13

Diener, E., Lucas, R. E., \& Scollon, C. N. (2006). Beyond the hedonic treadmill: Revising the adaptation theory of well-being. American Psychologist, 61(4), 305-314. https://doi.org/10.1037/0003-066X.61.4.305

Dirkzwager, A. J. E., Bramsen, I., Ader, H., \& Van Der Ploeg, H. M. (2005). Secondary traumatization in partners and parents of Dutch peacekeeping soldiers. Journal of Family Psychology, 19(2), 217-226. https://doi.org/10.1037/0893-3200.19.2.217 
Donnellan, M. B., Kenny, D. A., Trzesniewski, K. H., Lucas, R. E., \& Conger, R. D. (2012). Using trait-state models to evaluate the longitudinal consistency of global self-esteem from adolescence to adulthood. Journal of Research in Personality, 46(6), 634-645. https://doi.org/10.1016/j.jrp.2012.07.005

Dush, C. M. K., \& Amato, P. R. (2005). Consequences of relationship status and quality for subjective well-being. Journal of Social and Personal Relationships, 22(5), 607-627. https://doi.org/10.1177/0265407505056438

Dyrdal, G. M., \& Lucas, R. E. (2013). Reaction and adaptation to the birth of a child: A couple-level analysis. Developmental Psychology, 49(4), 749-761. https://doi.org/10.1037/a0028335

Ehrhardt, J. J., \& Saris, W. E. (2000). Stability of life satisfaction over time. Journal of Happiness Studies, 1(2), 177-205. https://doi.org/10.1023/A:1010084410679

Enders, C. K. (2001). The impact of nonnormality on full information maximum-likelihood estimation for structural equation models with missing data. Psychological Methods, 6(4), 352--370. https://doi.org/10.1037/1082-989X.6.4.352.

Faul, F., Erdfelder, E., Lang, A. G., \& Buchner, A. (2007). G*Power 3: A flexible statistical power analysis program for the social, behavioral, and biomedical sciences. Behavior Research Methods, 39(2), 175-191. https://doi.org/10.3758/bf03193146

Gagné, F. M., \& Lydon, J. E. (2004). Bias and accuracy in close relationships: An integrative review. Personality and Social Psychology Review, 8(4), 322-338. https://doi.org/10.1207/s15327957pspr0804_1

Galambos, N. L., Barker, E. T., \& Krahn, H. J. (2006). Depression, self-esteem, and anger in emerging adulthood: Seven-year trajectories. 42(2), 350-365. https://doi.org/10.1037/0012-1649.42.2.350

Galatzer-Levy, I. R., \& Bonanno, G. A. (2012). Beyond normality in the study of 
bereavement: Heterogeneity in depression outcomes following loss in older adults. Social Science and Medicine, 74(12), 1987-1994.

https://doi.org/10.1016/j.socscimed.2012.02.022

Glaesmer, H., Grande, G., Braehler, E., \& Roth, M. (2011). The German version of the satisfaction with life scale (SWLS). European Journal of Psychological Assessment, 27, 127-132. https://doi.org/10.1027/1015-5759/a000058

Hagedoorn, M., Sanderman, R., Bolks, H. N., Tuinstra, J., \& Coyne, J. C. (2008). Distress in couples coping with cancer: A meta-analysis and critical review of role and gender effects. Psychological Bulletin, 134(1), 1-30. https://doi.org/10.1037/0033-2909.134.1.1

Harris, M. A., \& Orth, U. (2019). The link between self-esteem and social relationships: A meta-analysis of longitudinal studies. Journal of Personality and Social Psychology, 119(6), 1459-1477. https://doi.org/10.1037/pspp0000265

Hatfield, E., Bensman, L., Thornton, P. D., \& Rapson, R. L. (2014). New perspectives on emotional contagion: A review of classic and recent research on facial mimicry and contagion. Interpersona, 8(2), 159-179. http://dx.doi.org/10.23668/psycharchives.2195

Hayslip Jr, B., Pruett, J. H., \& Caballero, D. M. (2015). The "how" and "when" of parental loss in adulthood: Effects on grief and adjustment. OMEGA-Journal of Death and Dying, 71(1), 3-18. https://doi.org/10.1177/0030222814568274

Holt-Lunstad, J. (2018). Why social relationships are important for physical health: A systems approach to understanding and modifying risk and protection. Annual Review of Psychology, 69, 437-458. https://doi.org/10.1146/annurev-psych-122216-011902

Infurna, F. J., \& Luthar, S. S. (2017). Parents' adjustment following the death of their child: Resilience is multidimensional and differs across outcomes examined. Journal of Research in Personality, 68, 38-53. https://doi.org/10.1016/j.jrp.2017.04.004 Infurna, F. J., \& Mayer, A. (2019). Repeated bereavement takes its toll on subjective well- 
being. Innovation in Aging, 3(4), 1-14. https://doi.org/10.1093/geroni/igz047

Infurna, F. J., Wiest, M., Gerstorf, D., Ram, N., Schupp, J., Wagner, G. G., \& Heckhausen, J. (2017). Changes in life satisfaction when losing one's spouse: Individual differences in anticipation, reaction, adaptation and longevity in the German Socio-economic Panel Study (SOEP). Ageing and Society, 37(5), 899-934.

https://doi.org/10.1017/S0144686X15001543

James, W. (1890). The principles of psychology (Vol. 1). New York: Henry Holt.

Jayawickreme, E., \& Blackie, L. E. R. (2014). Post-traumatic growth as positive personality change: Evidence, controversies and future directions. European Journal of Personality, 28(4), 312-331. https://doi.org/10.1002/per.1963

Jayawickreme, E., Infurna, F. J., Alajak, K., Blackie, L. E. R., Chopik, W. J., Chung, J. M., ... Zonneveld, R. (2020). Post-traumatic growth as positive personality change: Challenges, opportunities, and recommendations. Journal of Personality, 89, 145-165. https://doi.org/10.1111/jopy.12591

Joel, S., Eastwick, P. W., \& Finkel, E. J. (2018). Open sharing of data on close relationships and other sensitive social psychological topics: Challenges, tools, and future directions. Advances in Methods and Practices in Psychological Science, 1(1), 86-94. https://doi.org/10.1177/2515245917744281

Joiner, T. E., Katz, J., \& Angela, L. (1999). Harbingers of depressotypic reassurance seeking: Negative life events, increased anxiety, and decreased self-esteem. Personality and Social Psychology Bulletin, 25(5), 630-637.

https://doi.org/10.1177/0146167299025005008

Kahn, R. L., \& Antonucci, T. C. (1980). Convoys over the life course: Attachment, roles, and social support. Lifespan Development and Behavior, 3, 253-286.

Kenny, D.A., Kashy, D.A., \& Cook, W.L. (2006). Analyzing mixed independent variables: 
The Actor-Partner Interdependence Model. In D.A. Kenny, D.A. Kashy, \& W.L. Cook (Eds.), Dyadic data analysis (pp. 144-184). New York: Guilford Press.

Keyes, K. M., Pratt, C., Galea, S., McLaughlin, K. A., Koenen, K. C., \& Shear, M. K. (2014). The burden of loss: unexpected death of a loved one and psychiatric disorders across the life course in a national study. American Journal of Psychiatry, 171(8), 864-871

Kim, J., \& Hicks, J. A. (2015). Parental bereavement and the loss of purpose in life as a function of interdependent self-construal. Frontiers in Psychology, 6(July), 1-7. https://doi.org/10.3389/fpsyg.2015.01078

Kristiansen, C. B., Kjær, J. N., Hjorth, P., Andersen, K., \& Prina, A. M. (2019). The association of time since spousal loss and depression in widowhood: a systematic review and meta-analysis. Social Psychiatry and Psychiatric Epidemiology, 54, 781792. https://doi.org/10.1007/s00127-019-01680-3

Krueger, R. F. (1999). Personality traits in late adolescence predict mental disorders in early adulthood: A perspective-epidemiological study. Journal of Personality, 67(1), 39-65. https://doi.org/10.1111/1467-6494.00047

Kuster, F., \& Orth, U. (2013). The long-term stability of self-esteem: Its time-dependent decay and nonzero asymptote. Personality and Social Psychology Bulletin, 39(5), 677 690. https://doi.org/10.1177/0146167213480189

Langner, L. A., \& Furstenberg, F. F. (2019). After the burden is lifted: Caregivers' recovery of life satisfaction after the death or recovery of a spouse. The Journals of Gerontology: Series B, 75(10), 2170-2180. https://doi.org/10.1093/geronb/gbz117

Laurenceau, J. P., Barrett, L. F., \& Rovine, M. J. (2005). The interpersonal process model of intimacy in marriage: A daily-diary and multilevel modeling approach. Journal of Family Psychology, 19(2), 314 -323. https://doi.org/10.1037/0893-3200.19.2.314 Leary, M. R., \& Baumeister, R. F. (2000). The nature and function of self-esteem: Sociometer 
theory. In M. P. Zanna (Ed.), Advances in experimental social psychology, Vol. 32 (p. 162). Academic Press. https://doi.org/10.1016/S0065-2601(00)80003-9

Lemay, E. P., Jr., Clark, M. S., \& Feeney, B. C. (2007). Projection of responsiveness to needs and the construction of satisfying communal relationships. Journal of Personality and Social Psychology, 92(5), 834-853. https://doi.org/10.1037/0022-3514.92.5.834

Leopold, T., \& Lechner, C. M. (2015). Parents' death and adult well-being: gender, age, and adaptation to filial bereavement. Journal of Marriage and Family, 77(3), 747-760. https://doi.org/10.1111/jomf.12186

Lerner, M. J. (1980). The belief in a just world: A fundamental delusion. New York: Plenum. http://dx.doi.org/10.1007/978-1-4899-0448-5

Liu, W. M., Forbat, L., \& Anderson, K. (2019). Death of a close friend: Short and long-term impacts on physical, psychological and social well-being. PLoS ONE, 14(4), 1-17. https://doi.org/10.1371/journal.pone.0214838

Lucas, R E, Clark, A. E., Georgellis, Y., \& Diener, E. (2003). Reexamining adaptation and the set point model of happiness: Reactions to changes in marital status. Journal of Personality and Social Psychology, 84(3), 527-539. https://doi.org/Doi 10.1037/00223514.84.3.527

Lucas, R. E. (2007). Adaptation and the set-point model of subjective well-being: Does happiness change after major life events? Current Directions in Psychological Science, 16(2), 75-79. https://doi.org/10.1111/j.1467-8721.2007.00479.x

Lucas, R. E., \& Donnellan, M. B. (2007). How stable is happiness? Using the STARTS model to estimate the stability of life satisfaction. Journal of Research in Personality, 41(5), 1091-1098. https://doi.org/10.1016/j.jrp.2006.11.005

Luciano, E. C., \& Orth, U. (2017). Transitions in romantic relationships and development of self-esteem. Journal of Personality and Social Psychology, 112(2), 307-328. 
https://doi.org/10.1037/pspp0000109

Luhmann, M., Fassbender, I., Alcock, M., \& Haehner, P. (2020). A dimensional taxonomy of perceived characteristics of major life events. Journal of Personality and Social Psychology. Advance online publication. https://doi.org/10.1037/pspp0000291

Luhmann, M., Hofmann, W., Eid, M., \& Lucas, R. E. (2012). Subjective well-being and adaptation to life events: A meta-analysis. Journal of Personality and Social Psychology, 102(3), 592-615. https://doi.org/10.1037/a0025948

Luhmann, M., Weiss, P., Hosoya, G., \& Eid, M. (2014). Honey, I got fired! A longitudinal dyadic analysis of the effect of unemployment on life satisfaction in couples. Journal of Personality and Social Psychology, 107(1), 163-180. https://doi.org/10.1037/a0036394

Lundberg, T., Forinder, U., Olsson, M., Fürst, C. J., Årestedt, K., \& Alvariza, A. (2018). Bereavement stressors and psychosocial well-being of young adults following the loss of a parent - A cross-sectional survey. European Journal of Oncology Nursing, 35(May), 33-38. https://doi.org/10.1016/j.ejon.2018.05.004

MacCallum, R. C., Browne, M. W., \& Cai, L. (2006). Testing differences between nested covariance structure models: Power analysis and null hypotheses. Psychological Methods, 11, 19-35. https://doi.org/10.1037/1082-989x.11.1.19.

Magnusson, D. (1990). Personality development from an interactional perspective. In L. Pervin (Ed.), Handbook of personality: Theory and research (pp. 193-222). New York, NY: Guilford Press.

Mahadevan, N., Gregg, A. P., \& Sedikides, C. (2019). Is self-regard a sociometer or a hierometer? Self-esteem tracks status and inclusion, narcissism tracks status. Journal of Personality and Social Psychology, 116(3), 444-466. https://doi.org/10.1037/pspp0000189

Măirean, C. (2016). Secondary traumatic stress and posttraumatic growth: Social support as a 
moderator. The Social Science Journal, 53(1), 14-21.

https://doi.org/10.1016/j.soscij.2015.11.007

Mancini, A. D., Prati, G., \& Black, S. (2011). Self-worth mediates the effects of violent loss on PTSD symptoms. Journal of Traumatic Stress, 24(1), 116-120.

https://doi.org/10.1002/jts.20597

Mangelsdorf, J., Eid, M., \& Luhmann, M. (2019). Does growth require suffering? A systematic review and meta-analysis on genuine posttraumatic and postecstatic growth. Psychological Bulletin, 145(3), 302-338. https://doi.org/10.1037/bul0000173

McAdams, D. P., \& Olson, B. D. (2010). Personality development: Continuity and change over the life course. Annual Review of Psychology, 61, 517-542.

https://doi.org/10.1146/annurev.psych.093008.100507

Michael, C., \& Cooper, M. (2013). Post-traumatic growth following bereavement: A systematic review of the literature. Counselling Psychology Review, 28(4), 18-33.

Miller, M. D. (2012). Complicated grief in late life. Dialogues in clinical neuroscience, 14(2), 195. doi: 10.31887/DCNS.2012.14.2/mmiller

Miller, N. B., Smerglia, V. L., \& Bouchet, N. (2004). Women's adjustment to widowhood: Does social support matter? Journal of Women \& Aging, 16(3-4), 149-167. https://doi.org/10.1300/J074v16n03_11

Montpetit, M. A., Bergeman, C. S., \& Bisconti, T. L. (2010). The self-concept and conjugal loss: Evidence for structural change. Death Studies, 34(7), 606-624. https://doi.org/10.1080/07481187.2010.495522

Moor, N., \& de Graaf, P. M. (2016). Temporary and long-term consequences of bereavement on happiness. Journal of Happiness Studies, 17(3), 913-936. https://doi.org/10.1007/s10902-015-9624-x

Murrell, S. A., Meeks, S., \& Walker, J. (1991). Protective functions of health and self-esteem 
against depression in older adults facing illness or bereavement. Psychology and Aging, 6(3), 352-360. https://doi.org/10.1037/0882-7974.6.3.352

Naef, R., Ward, R., Mahrer-Imhof, R., \& Grande, G. (2013). Characteristics of the bereavement experience of older persons after spousal loss: An integrative review. International Journal of Nursing Studies, 50(8), 1108-1121. https://doi.org/10.1016/j.ijnurstu.2012.11.026

Neff, L. A., \& Karney, B. R. (2007). Stress crossover in newlywed marriage: A longitudinal and dyadic perspective. Journal of Marriage and Family, 69(3), 594-607. https://doi.org/10.1111/j.1741-3737.2007.00394.x

Neyer, F. J., Mund, M., Zimmermann, J., \& Wrzus, C. (2014). Personality-relationship transactions revisited. Journal of Personality, 82(6), 539-550. https://doi.org/10.1111/jopy.12063

Neyer, F. J., \& Lang, F. R. (2003). Blood is thicker than water: Kinship orientation across adulthood. Journal of Personality and Social Psychology, 84(2), 310-321. https://doi.org/10.1037/0022-3514.84.2.310

Oberski, D. (2014). lavaan.survey: An R package for complex survey analysis of structural equation models. Journal of Statistical Software, 57, 1-27. http://dx.doi.org/10.18637/jss.v057.i01

Orth, U., Erol, R. Y., Ledermann, T., \& Grob, A. (2018). Codevelopment of well-being and self-esteem in romantic partners: Disentangling the effects of mutual influence and shared environment. Developmental Psychology, 54(1), 151-166. https://doi.org/10.1037/dev0000400

Orth, U, Robins, R. W., \& Meier, L. L. (2009). Disentangling the effects of low self-esteem and stressful events on depression: findings from three longitudinal studies. Journal of Personality and Social Psychology, 97(2), 307-321. https://doi.org/10.1037/a0015645 
Orth, U. (2013). How large are actor and partner effects of personality on relationship satisfaction? The importance of controlling for shared method variance. Personality and Social Psychology Bulletin, 39(10), 1359-1372.

https://doi.org/10.1177/0146167213492429

Orth, U., \& Luciano, E. C. (2015). Self-esteem, narcissism, and stressful life events: Testing for selection and socialization. Journal of Personality and Social Psychology, 109(4), 707-721. https://doi.org/10.1037/pspp0000049

Orth, U., Erol, R. Y., \& Luciano, E. C. (2018). Development of self-esteem from age 4 to 94 Years: A meta-analysis of longitudinal studies. Psychological Bulletin, 144(10), 10451080. https://doi.org/10.1037/bul0000161

Ozer, E. J., Best, S. R., Lipsey, T. L., \& Weiss, D. S. (2008). Predictors of posttraumatic stress disorder and symptoms in adults: A meta-analysis. Psychological Trauma: Theory, Research, Practice, and Policy, 129(1), 52-73. https://doi.org/10.1037/1942-9681.s.1.3

Pasupathi, M., Mansour, E., \& Brubaker, J. R. (2007). Developing a life story: Constructing relations between self and experience in autobiographical narratives. Human Development, 50(2-3), 85-110. doi: 10.1159/000100939

Peterson, R. A., \& Brown, S. P. (2005). On the use of the beta coefficients in meta-analysis. Journal of Applied Psychology, 90(1), 175-181. https://doi.org/ 10.1037/00219010.90 .1 .175

Pohlkamp, L., Kreicbergs, U., \& Sveen, J. (2019). Bereaved mothers' and fathers' prolonged grief and psychological health 1 to 5 years after loss-A nationwide study. PsychoOncology, 28(7), 1530-1536. https://doi.org/10.1002/pon.5112

Prati, G., \& Pietrantoni, L. (2009). Optimism, social support, and coping strategies as factors contributing to posttraumatic growth: A meta-analysis. Journal of Loss and Trauma, 14(5), 364-388. https://doi.org/10.1080/15325020902724271 
Raffaelli, M., Andrade, F. C., Wiley, A. R., Sanchez-Armass, O., Edwards, L. L., \& Aradillas-Garcia, C. (2013). Stress, social support, and depression: A test of the stressbuffering hypothesis in a Mexican sample. Journal of Research on Adolescence, 23(2), 283-289. https://doi.org/10.1111/jora.12006

Randall, A. K., \& Bodenmann, G. (2009). The role of stress on close relationships and marital satisfaction. Clinical Psychology Review, 29(2), 105-115. https://doi.org/10.1016/j.cpr.2008.10.004

Reis, H. T., \& Gable, S. L. (2015). Responsiveness. Current Opinions in Psychology, 1, 6771. Selcuk, E., Stanton, S. C., Slatcher, R. B., \& Ong, A. D. (2016). Perceived partner responsiveness predicts better sleep quality through lower anxiety. Social Psychological and Personality Science, 8(1), 83-92. https://doi.org/10.1037/pspi0000134

Reis, H. T., \& Shaver, P. (1988). Intimacy as an interpersonal process. Handbook of personal relationships.

Reitz, A. K., Luhmann, M., Bleidorn, W., \& Denissen, J. J. A. (2021, June 10). Unraveling the complex relationship between work transitions and self-esteem and life satisfaction. https://doi.org/10.31234/osf.io/y2akc

Reitz, A. K., Shrout, P. E., Denissen, J. J., Dufner, M., \& Bolger, N. (2020). Self-esteem change during the transition from university to work. Journal of Personality, 88(4), 689702. https://doi.org/10.1111/jopy.12519

Renshaw, K. D., Allen, E. S., Rhoades, G. K., Blais, R. K., Markman, J., \& Stanley, S. M. (2012). Combat-Related PTSD: Secondary Traumatic Stress or General. 25(4), 461469. https://doi.org/10.1037/a0023994.Distress

Robins, R. W., \& Trzesniewski, K. H. (2005). Self-esteem development across the lifespan. Current Directions in Psychological Science, 14(3), 158-162. https://doi.org/10.1111/j.0963-7214.2005.00353.x 
Røsand, G. M. B., Slinning, K., Eberhard-Gran, M., Røysamb, E., \& Tambs, K. (2012). The buffering effect of relationship satisfaction on emotional distress in couples. BMC Public Health, 12(1), 66. https://doi.org/10.1186/1471-2458-12-66

Rosenberg, M. (1965). Society and the adolescent self-image. Princeton, NJ: Princeton University Press.

Sameroff, A. (2010). A unified theory of development: A dialectic integration of nature and nurture. Child Development, 81(1), 6-22. https://doi.org/10.1111/j.14678624.2009.01378.x

Samios, C., \& Baran, S. (2018). Couple adjustment to a stressful life event: a dyadic investigation of the roles of positive reframing and perceived benefits. Anxiety, Stress and Coping, 31(2), 188-205. https://doi.org/10.1080/10615806.2017.1420173

Schermelleh-Engel, K., Moosbrugger, H., \& Müller, H. (2003). Evaluating the fit of structural equation models: Tests of significance and descriptive goodness-of-fit measures. Methods of Psychological Research, 8, 23-74.

Schwarzer, R., \& Knoll, N. (2007). Functional roles of social support within the stress and coping process: A theoretical and empirical overview. International Journal of Psychology, 42(4), 243-252.

Shapiro, E. R. (2008). Whose recovery, of what? Relationships and environments promoting grief and growth. Death Studies, 32(1), 40-58. https://doi.org/10.1080/07481180701741277

Shi, B. (2021). Perceived social support as a moderator of depression and stress in college students. Social Behavior and Personality: An International Journal, 49(1), 1-9. https://doi.org/10.2224/sbp.9893

Shrout, P. E., Herman, C. M., \& Bolger, N. (2006). The costs and benefits of practical and emotional support on adjustment: A daily diary study of couples experiencing acute 
stress. Personal Relationships, 13(1), 115-134. https://doi.org/10.1111/j.14756811.2006.00108.x

Spahni, S., Bennett, K. M., \& Perrig-Chiello, P. (2016). Psychological adaptation to spousal bereavement in old age: The role of trait resilience, marital history, and context of death. Death Studies, 40(3), 182-190. https://doi.org/10.1080/07481187.2015.1109566

Stroebe, M., Schut, H., \& Stroebe, W. (2007). Health outcomes of bereavement. The Lancet, 370(9603), 1960-1973. https://doi.org/10.1016/S0140-6736(07)61816-9

Stroebe, W., Zech, E., Stroebe, M. S., \& Abakoumkin, G. (2005). Does social support help in bereavement? Journal of Social and Clinical Psychology, 24(7), 1030-1050. https://doi.org/10.1521/jscp.2005.24.7.1030

Tedeschi, R. G., \& Calhoun, L. G. (2004). Posttraumatic growth: Conceptual foundations and empirical evidence. Psychological Inquiry, 15(1), 1-18. https://doi.org/10.1207/s15327965pli1501_01

Tetzner, J., Becker, M., \& Baumert, J. (2016). Still Doing Fine? The interplay of negative life events and self-esteem during young adulthood. European Journal of Personality, 30(4), 358-373. https://doi.org/10.1002/per.2066

Tseng, Y. F., Cheng, H. R., Chen, Y. P., Yang, S. F., \& Cheng, P. T. (2017). Grief reactions of couples to perinatal loss: A one-year prospective follow-up. Journal of Clinical Nursing, 26(23-24), 5133-5142. https://doi.org/10.1111/jocn.14059

Urry, H. L., \& Gross, J. J. (2010). Emotion regulation in older age. Current Directions in Psychological Science, 19(6), 352-357. https://doi.org/10.1177/0963721410388395

Utz, R. L., Swenson, K. L., Caserta, M., Lund, D., \& DeVries, B. (2014). Feeling lonely versus being alone: Loneliness and social support among recently bereaved persons. Journals of Gerontology - Series B Psychological Sciences and Social Sciences, 69(1), 85-94. https://doi.org/10.1093/geronb/gbt075 
van Baarsen, B. (2002). Theories on coping with loss: The impact of social support and selfesteem on adjustment to emotional and social loneliness following a partner's death in later life. Journals of Gerontology - Series B Psychological Sciences and Social Sciences, 57(1), 33-42. https://doi.org/10.1093/geronb/57.1.S33

van Lange, P. A. M., \& Balliet, D. (2015). Interdependence theory. In M. Mikulincer, P. R. Shaver, J. A. Simpson, \& J. F. Dovidio (Eds.), APA handbooks in psychology®. APA handbook of personality and social psychology, Vol. 3. Interpersonal relations (p. 6592). American Psychological Association. https://doi.org/10.1037/14344-003 von Collani, G., \& Herzberg, P. Y. (2003). Eine revidierte Fassung der deutschsprachigen Skala zum Selbstwertgefühl von Rosenberg. Zeitschrift für Differentielle und Diagnostische Psychologie, 24(1), 3-7.

van Scheppingen, M. A., Chopik, W. J., Bleidorn, W., \& Denissen, J. J. (2019). Longitudinal actor, partner, and similarity effects of personality on well-being. Journal of Personality and Social Psychology, 117(4), e51. https://doi.org/10.1037/pspp0000211

Waugh, A., Kiemle, G., \& Slade, P. (2018). What aspects of post-traumatic growth are experienced by bereaved parents? A systematic review. European Journal of Psychotraumatology, 9(1), 1506230. https://doi.org/10.1080/20008198.2018.1506230

Wofford, N., Defever, A. M., \& Chopik, W. J. (2019). The vicarious effects of discrimination: How partner experiences of discrimination affect individual health. Social Psychological and Personality Science, 10(1), 121-130. https://doi.org/10.1177/1948550617746218 Wonch Hill, P., Cacciatore, J., Shreffler, K. M., \& Pritchard, K. M. (2017). The loss of self: The effect of miscarriage, stillbirth, and child death on maternal self-esteem. Death Studies, 41(4), 226-235. https://doi.org/10.1080/07481187.2016.1261204 
Wünsche, J., Weidmann, R., \& Grob, A. (2020). Until death do us part: The codevelopment of life satisfaction in couples preceding the death of one partner. Journal of Personality and Social Psychology, 119(4), 881-900. https://doi.org/10.1037/pspi0000228 


\section{Footnotes}

${ }^{1}$ This approach is superior to a tailored approach (one that uses the closest pre- and post-event assessment per individual) for the following reasons: a) In a tailored approach, we might have APIMs for partners with different pre- and post-event assessment waves, i.e., different intervals (e.g., if the partners experienced a bereavement between different waves), which is not indicated since we are interested in their co-development during the same time interval. b) $n=28$ participants experienced the event during or very close to the assessments of waves 2 and 3. For them, waves 2 and 3, respectively, could not be used for pre- or post-event assessments, as some of the daily assessments of the same wave might have been before or after the bereavement. Using Wave 1 as the Time 1 pre-event and Wave 4 as the Time 2 postevent assessment is clear cut, as the loss occurred before Wave 4 and after Wave 1. c) Using Wave 1 instead of the closest pre-event assessment has the advantage that potential anticipatory effects would have less of an impact (Infurna et al., 2017). d) This approach is more straightforward when it comes to the control group for whom an arbitrary pre- and postevent measure would have to be assigned (as they did not experience the bereavement event).

${ }^{2}$ In addition to using a residualized approach, we ran all reported models including a difference score of self-esteem or life satisfaction (i.e., self-esteem T2 - self-esteem T1) as outcome variable (instead of their levels at T2). As for the residualized approach, we controlled for both partners' T1 baseline levels. Difference scores have been used in previous studies on bereavement effects on personality (e.g., Chopik, 2008). Results were virtually identical to those obtained from the residualized approach in terms of direction, significance, and size. We do not discuss them further. The results can be obtained from the first author.

${ }^{3}$ The analysis for Hypothesis 3 included only bereaved individuals because only they had records of the relationship to the deceased person (moderator). As some couples had only 
one partner who experienced a bereavement during the study, we were not able to apply a moderated actor-partner interdependence model for this analysis.

${ }^{4}$ Most of the models' variance-covariance matrices of the estimated parameters did not seem to be positive definite, which was likely due to the inclusion of dichotomous predictors in the models.

${ }^{5}$ For those with a bereavement, the bereavement determined which of the 4 overall assessments we had was to be used for the second assessment (i.e., the first post-event assessment). For those without a bereavement, the second assessment is less easy to determine. Since we need the interval between their first and second assessment to be comparable to that of the bereavement group to obtain a suitable control group, we acted as follows: We randomly assigned those without a bereavement experience to one of the 5 cohorts of the bereavement group (i.e., bereavement between waves 1, 2, 3 or during 2 or 3 ). The cohorts determined which post-bereavement assessments were used. For example, $19.4 \%$ of the bereaved experienced the event between W1 and W2 (i.e., cohort 1), hence the assessment at W2 was used as the new post-event assessment. From the control group, we therefore also randomly grouped $19.4 \%$ into cohort 1 and used the assessment at W2 as their post assessment. This procedure ensured that the same percentage of post-event assessments was chosen for the control group as for the bereaved and, hence, that the intervals between their first and second assessments were comparable. 


\section{Table 1}

Descriptive Statistics and Bivariate Correlations of the Study Variables for Bereaved and Non-Bereaved Individuals

\begin{tabular}{|c|c|c|c|c|c|c|c|}
\hline & 1 & 2 & 3 & 4 & 5 & 6 & 7 \\
\hline 1. Self-esteem T1 & - & .78 & .66 & .56 & .14 & .16 & \\
\hline 2. Self-esteem T2 & .75 & - & .61 & .64 & .05 & .20 & .13 \\
\hline 3. Life satisfaction $\mathrm{T} 1$ & .65 & .49 & - & .76 & .18 & .26 & .13 \\
\hline 4. Life satisfaction $\mathrm{T} 2$ & .49 & .55 & .70 & - & .12 & .25 & .22 \\
\hline 5. Support & .08 & .06 & .13 & .16 & - & .32 & .23 \\
\hline 6. Responsiveness & .21 & .21 & .31 & .35 & .32 & - & .76 \\
\hline 7. Disclosure & .14 & .13 & .21 & .27 & .34 & .72 & - \\
\hline$M$ bereaved & 3.32 & 3.33 & 3.83 & 3.97 & 1.26 & 5.56 & 3.50 \\
\hline$S D$ bereaved & 0.53 & 0.56 & 0.77 & 0.75 & 0.18 & 0.75 & 0.57 \\
\hline$M$ not bereaved & 3.26 & 3.31 & 3.84 & 4.01 & 1.24 & 5.48 & 3.46 \\
\hline$S D$ not bereaved & 0.55 & 0.55 & 0.73 & 0.70 & 0.19 & 0.75 & 0.52 \\
\hline$M_{\text {total }}$ & 3.27 & 3.30 & 3.83 & 4.01 & 1.24 & 5.49 & 3.46 \\
\hline$S D$ total & 0.55 & 0.55 & 0.74 & 0.71 & 0.19 & 0.75 & 0.53 \\
\hline
\end{tabular}

Note. Significant correlations $(p<.05)$ are displayed in bold. Correlations above the diagonal are for bereaved individuals, correlations below the diagonal are for non-bereaved individuals. $M=$ mean, $S D=$ standard deviation. Responsiveness contains both responsiveness and closeness scales. 
Table 2

Results of the Actor-Partner Interdependence Models

\begin{tabular}{|c|c|c|c|c|}
\hline \multirow[t]{3}{*}{ Predictor } & \multicolumn{4}{|c|}{ Self-esteem T2 } \\
\hline & \multicolumn{2}{|c|}{ Actor effect } & \multicolumn{2}{|c|}{ Partner effect } \\
\hline & $b[95 \% \mathrm{CI}]$ & $p$ & $b[95 \% \mathrm{CI}]$ & $p$ \\
\hline Self-esteem T1 & $.42[.40, .44]$ & $<.001$ & $.04[.01, .06]$ & .001 \\
\hline \multirow[t]{3}{*}{ Bereavement } & $.00[-.06, .06]$ & .94 & $-.05[-.11, .02]$ & .15 \\
\hline & \multicolumn{4}{|c|}{ Life satisfaction T2 } \\
\hline & \multicolumn{2}{|c|}{ Actor effect } & \multicolumn{2}{|c|}{ Partner effect } \\
\hline Predictor & $b[95 \% \mathrm{CI}]$ & $p$ & $b[95 \% \mathrm{CI}]$ & $p$ \\
\hline Life satisfaction $\mathrm{T} 1$ & $.49[.45, .53]$ & $<.001$ & $.06[.02, .09]$ & .001 \\
\hline Bereavement & $-.04[-.12, .04]$ & .37 & $.00[-.08, .08]$ & .95 \\
\hline
\end{tabular}

Note. Bold regression weights $(b)$ are significant $(p<.05)$. Actor and partner effects are set equal across female and male partners. The analyses controlled for average couple age and the time distance between T1 and T2. $N_{\text {couples }}=619$. 
IN GOOD TIMES AND IN BAD

Table 3

Results of the Moderation Path Models with Type of Lost Relationship as

Moderator

\begin{tabular}{lcc}
\hline \multicolumn{1}{c}{ Predictor } & \multicolumn{2}{c}{ Self-esteem T2 } \\
\cline { 2 - 3 } & $b[95 \% \mathrm{CI}]$ & $p$ \\
\hline Self-esteem T1 & $.55[.40, .69]$ & $<.001$ \\
Type of lost relationship & $.01[-.09, .10]$ & .88 \\
Self-esteem T1 x type of lost relationship & $-.05[-.14, .04]$ & .25 \\
\hline \multicolumn{1}{c}{ Predictor } & Life satisfaction T2 \\
\cline { 2 - 3 } & $b[95 \% \mathrm{CI}]$ & $p$ \\
\hline Life satisfaction T1 & $\mathbf{. 5 2}[.28, .76]$ & $<.001$ \\
Type of lost relationship & $.08[-.06, .22]$ & .24 \\
Life satisfaction T1 x type of lost relationship & $.02[-.13, .17]$ & .83 \\
\hline
\end{tabular}

Note. Bold regression weights $(b)$ are significant $(p<.05)$. The analyses

controlled for age and the time distance between T1 and T2. $N=216$ bereaved individuals. Type of lost relationship was coded $1=$ others and $2=$ close relative. 
IN GOOD TIMES AND IN BAD

Table 4

Results of the Moderated Actor-Partner Interdependence Models with Social Support as Moderator

\begin{tabular}{|c|c|c|c|c|}
\hline \multirow[t]{3}{*}{ Predictor } & \multicolumn{4}{|c|}{ Self-esteem T2 } \\
\hline & \multicolumn{2}{|c|}{ Actor effect } & \multicolumn{2}{|c|}{ Partner effect } \\
\hline & $b[95 \% \mathrm{CI}]$ & $p$ & $b[95 \% \mathrm{CI}]$ & $p$ \\
\hline Self-esteem T1 & $.42[.40, .44]$ & $<.001$ & $\mathbf{. 0 3}[.01, .06]$ & .001 \\
\hline Bereavement & $.00[-.06, .05]$ & .91 & $-.04[-.10, .02]$ & .17 \\
\hline Support* & $-.02[-.10, .05]$ & .53 & & \\
\hline \multirow[t]{3}{*}{ Bereavement $\mathrm{x}$ support } & $-.03[-.10, .04]$ & .44 & $.05[-.02, .11]$ & .20 \\
\hline & \multicolumn{4}{|c|}{ Life satisfaction $\mathrm{T} 2$} \\
\hline & \multicolumn{2}{|c|}{ Actor effect } & \multicolumn{2}{|c|}{ Partner effect } \\
\hline Predictor & $b[95 \% \mathrm{CI}]$ & $p$ & $b[95 \% \mathrm{CI}]$ & $p$ \\
\hline Self-esteem T1 & $.49[.45, .52]$ & $<.001$ & $\mathbf{. 0 6}[.02, .09]$ & .002 \\
\hline Bereavement & $-.04[-.12, .04]$ & .31 & $.00[-.08, .08]$ & .93 \\
\hline Support* & $.04[-.09, .16]$ & .55 & & \\
\hline Bereavement $\mathrm{x}$ support & $-.03[-.11, .06]$ & .56 & $.02[-.07, .12]$ & .62 \\
\hline
\end{tabular}

Note. Bold regression weights $(b)$ are significant $(p<.05)$. Actor and partner effects are set equal across female and male partners. The analyses controlled for average couple age and the time distance between $\mathrm{T} 1$ and T2. $N_{\text {couples }}=619 . *$ The main effect is shown as an actor effect but can be considered as a couple-level effect on the individuals' outcomes, as it is a composite score of both partners' reports on this relationship characteristic. 
IN GOOD TIMES AND IN BAD

Table 5

Results of the Moderated Actor-Partner Interdependence Models with

Responsiveness as Moderator

\begin{tabular}{|c|c|c|c|c|}
\hline \multirow[t]{3}{*}{ Predictor } & \multicolumn{4}{|c|}{ Self-esteem T2 } \\
\hline & \multicolumn{2}{|c|}{ Actor effect } & \multicolumn{2}{|c|}{ Partner effect } \\
\hline & $b[95 \% \mathrm{CI}]$ & $p$ & $b[95 \% \mathrm{CI}]$ & $p$ \\
\hline Self-esteem T1 &. $\mathbf{4 2}[.39, .44]$ & $<.001$ & $\mathbf{. 0 3}[.01, .05]$ & .005 \\
\hline Bereavement & $.00[-.06, .06]$ & .89 & $-.05[-.11, .02]$ & .16 \\
\hline Responsiveness* & $.00[-.07, .07]$ & .97 & & \\
\hline Bereavement $\mathrm{x}$ responsiveness & $.02[-.06, .10]$ & .64 & $.00[-.09, .09]$ & .98 \\
\hline \multirow[t]{3}{*}{ Predictor } & \multicolumn{4}{|c|}{ Life satisfaction T2 } \\
\hline & \multicolumn{2}{|c|}{ Actor effect } & \multicolumn{2}{|c|}{ Partner effect } \\
\hline & $b[95 \% \mathrm{CI}]$ & $p$ & $b[95 \% \mathrm{CI}]$ & $p$ \\
\hline Self-esteem T1 & $.47[.43, .51]$ & $<.001$ & $\mathbf{. 0 4}[.01, .08]$ & .02 \\
\hline Bereavement & $-.03[-.11, .05]$ & .43 & $-.01[-.09, .07]$ & .79 \\
\hline Responsiveness* & $.10[-.03, .23]$ & .13 & & \\
\hline Bereavement $\mathrm{x}$ responsiveness & $-.06[-.16, .04]$ & .25 & $.04[-.06, .14]$ & .38 \\
\hline
\end{tabular}

Note. Bold regression weights $(b)$ are significant $(p<.05)$. Actor and partner effects are set equal across female and male partners. The analyses controlled for average couple age and the time distance between $\mathrm{T} 1$ and T2. $N_{\text {couples }}=$ 619. *The main effect is shown as an actor effect but can be considered as a couple-level effect on the individuals' outcomes, as it is a composite score of both partners' reports on this relationship characteristic. 


\section{Table 6}

Results of the Moderated Actor-Partner Interdependence Models with Self-

\section{Disclosure as Moderator}

\begin{tabular}{|c|c|c|c|c|}
\hline \multirow[t]{3}{*}{ Predictor } & \multicolumn{4}{|c|}{ Self-esteem T2 } \\
\hline & \multicolumn{2}{|c|}{ Actor effect } & \multicolumn{2}{|c|}{ Partner effect } \\
\hline & $b[95 \% \mathrm{CI}]$ & $p$ & $b[95 \% \mathrm{CI}]$ & $p$ \\
\hline Self-esteem T1 & $\mathbf{4 2}[.40, .44]$ & $<.001$ & $\mathbf{. 0 3}[.01, .05]$ & .002 \\
\hline Bereavement & $-.01[-.06, .05]$ & .87 & $-.05[-.11, .02]$ & .16 \\
\hline Disclosure* & $-.02[-.09, .04]$ & .47 & & \\
\hline Bereavement $\mathrm{x}$ disclosure & $.03[-.03, .09]$ & .30 & $.00[-.06, .06]$ & $>.99$ \\
\hline \multirow[t]{3}{*}{ Predictor } & \multicolumn{4}{|c|}{ Life satisfaction $\mathrm{T} 2$} \\
\hline & \multicolumn{2}{|c|}{ Actor effect } & \multicolumn{2}{|c|}{ Partner effect } \\
\hline & $b[95 \% \mathrm{CI}]$ & $p$ & $b[95 \% \mathrm{CI}]$ & $p$ \\
\hline Self-esteem T1 & $.47[.44, .51]$ & $<.001$ & $\mathbf{. 0 5}[.01, .08]$ & .007 \\
\hline Bereavement & $-.03[-.11, .05]$ & .42 & $-.01[-.09, .07]$ & .79 \\
\hline Disclosure* & $.04[-.10, .18]$ & .56 & & \\
\hline Bereavement $\mathrm{x}$ disclosure & $-.03[-.12, .06]$ & .47 & $.07[-.02, .16]$ & .15 \\
\hline
\end{tabular}

Note. Bold regression weights $(b)$ are significant $(p<.05)$. Actor and partner effects are set equal across female and male partners. The analyses controlled for average couple age and the time distance between $\mathrm{T} 1$ and T2. $N_{\text {couples }}=619 . *$ The main effect is shown as an actor effect but can be considered as a couple-level effect on the individuals' outcomes, as it is a composite score of both partners' reports on this relationship characteristic. 


\section{Figure 1}

Actor-Partner Interdependence Model with Self-Esteem at T2 as Outcome

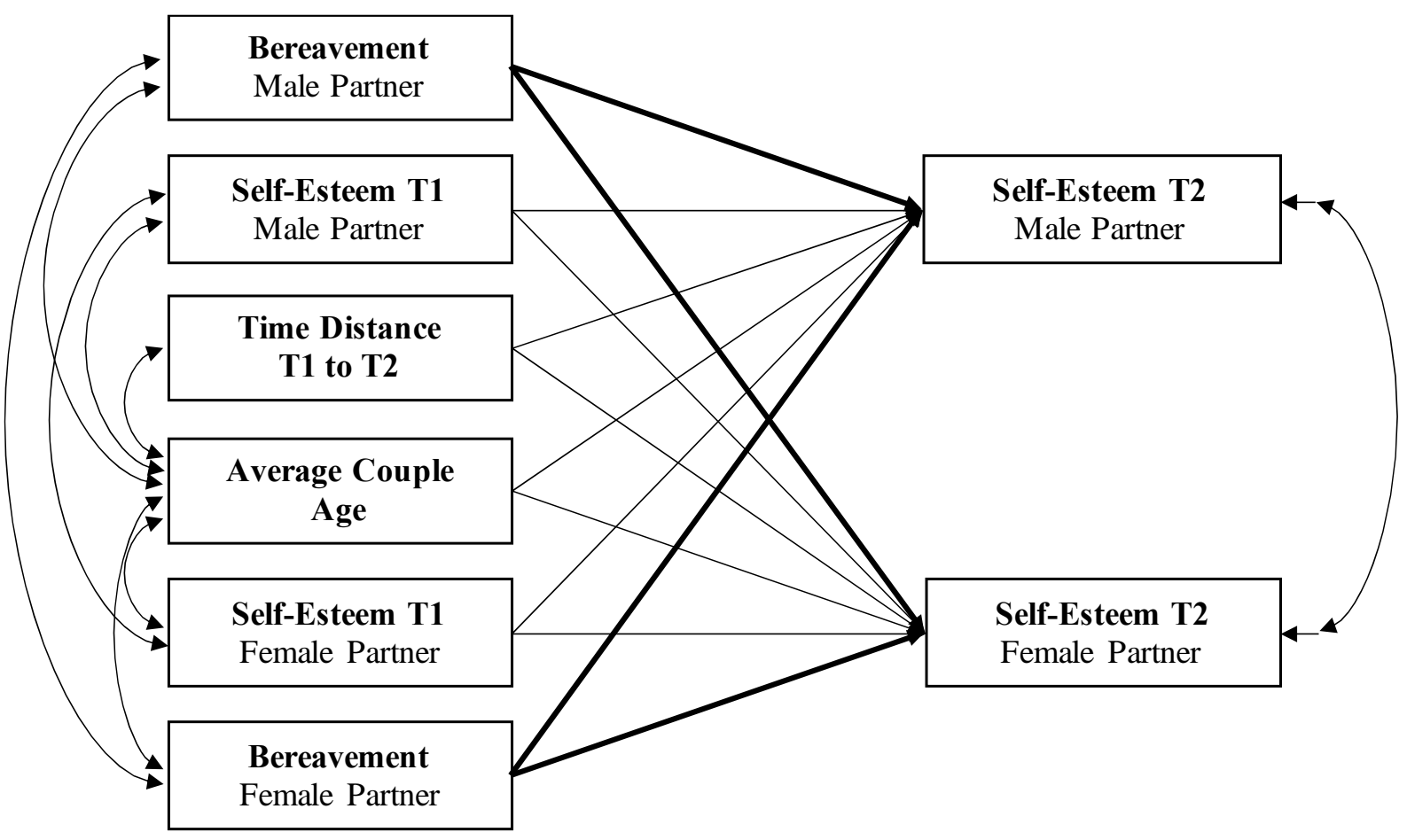

Note. Arrows in bold are the pre-registered hypothesized actor and partner effects. 


\section{Figure 2}

Mean Changes in Self-Esteem of Non-Bereaved and Bereaved Individuals

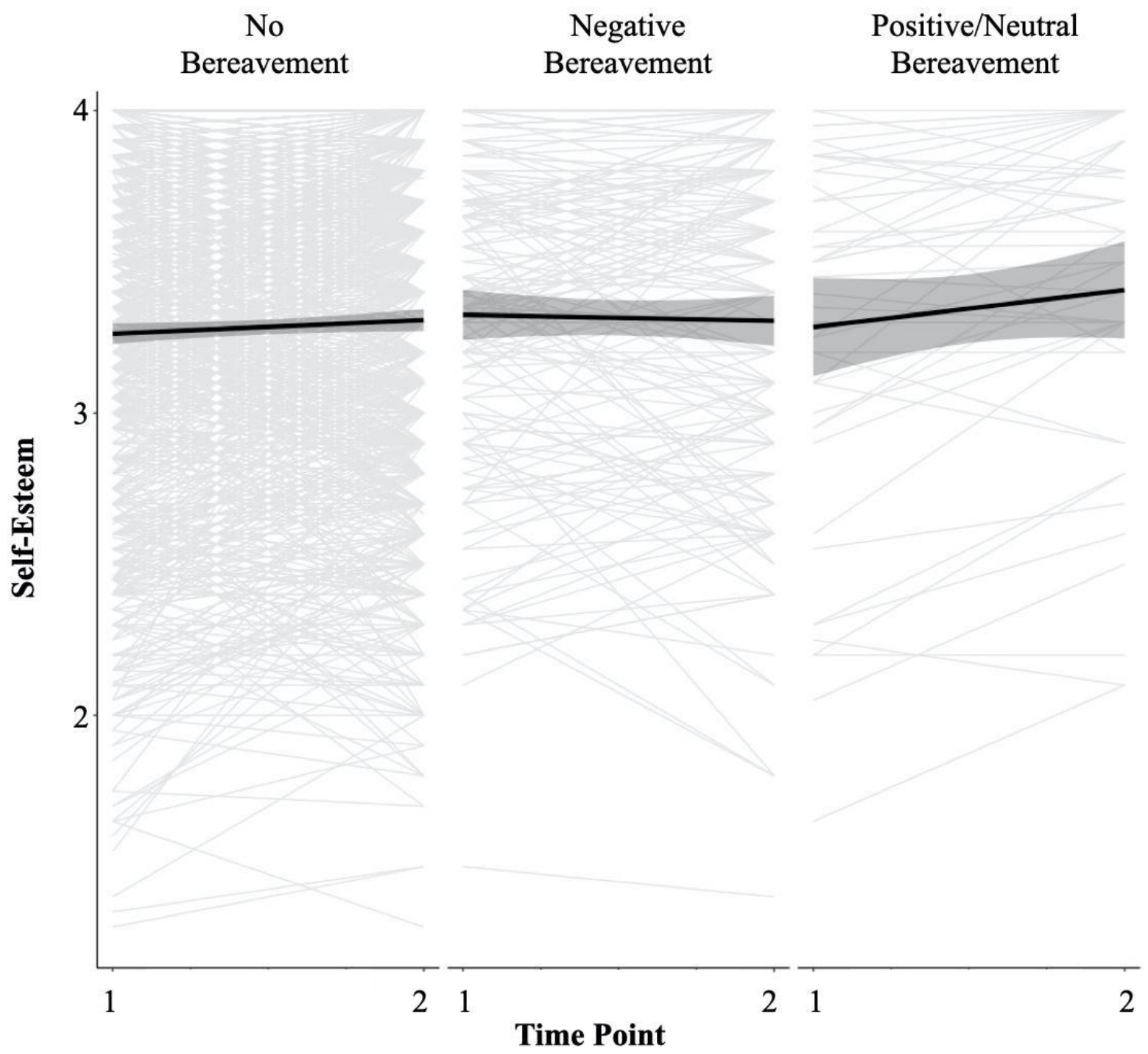

Note. Self-esteem changes in the negative bereavement group differed significantly from the positive/neutral bereavement group $(p<.01)$. 